University of Louisville

ThinkIR: The University of Louisville's Institutional Repository

Electronic Theses and Dissertations

$5-2020$

\title{
Tobacco-derived aldehydes: platelet activation, thrombosis, and the role of TRPA1.
}

Andre Dwayne Richardson

University of Louisville

Follow this and additional works at: https://ir.library.louisville.edu/etd

Part of the Cardiovascular Diseases Commons, and the Toxicology Commons

\section{Recommended Citation}

Richardson, Andre Dwayne, "Tobacco-derived aldehydes: platelet activation, thrombosis, and the role of TRPA1." (2020). Electronic Theses and Dissertations. Paper 3432.

https://doi.org/10.18297/etd/3432

This Master's Thesis is brought to you for free and open access by ThinkIR: The University of Louisville's Institutional Repository. It has been accepted for inclusion in Electronic Theses and Dissertations by an authorized administrator of ThinkIR: The University of Louisville's Institutional Repository. This title appears here courtesy of the author, who has retained all other copyrights. For more information, please contact thinkir@louisville.edu. 
TOBACCO-DERIVED ALDEHYDES: PLATELET ACTIVATION, THROMBOSIS, AND THE ROLE OF TRPA1

By

Andre Dwyane Richardson

B.S., Nazareth College of Rochester, 2016

\begin{abstract}
A Thesis
Submitted to the Faculty of the School of Medicine of the University of Louisville

In Partial Fulfillment of the Requirements for the Degree of

Master of Science

in Pharmacology and Toxicology

Department of Pharmacology and Toxicology

University of Louisville

Louisville, KY
\end{abstract}

May 2020 
Copyright 2019 by Andre Dwyane Richardson

All rights reserved 

TOBACCO-DERIVED ALDEHYDES: PLATELET ACTIVATION, THROMBOSIS, AND THE ROLE OF TRPA1

$$
\text { By }
$$

Andre Dwyane Richardson

B.S., Nazareth College of Rochester, 2016

Thesis Approved on

$11 / 12 / 2019$

by the following Thesis Committee:

\begin{tabular}{l}
\hline Daniel J. Conklin, Ph.D. \\
\hline Leah J. Siskind, Ph.D. \\
\hline Sanjay Srivastava, Ph.D. \\
\hline
\end{tabular}

Timothy E. O'Toole, Ph.D.

Stanley E. D'Souza 


\section{ACKNOWLEDGEMENTS}

I am incredibly appreciative of my mentor, Dr. Daniel J. Conklin, for his support, guidance, and encouragement. Without his assistance, I would not have this opportunity to study in research.

Thank you to Drs. Stanley D'Souza and Tatiana Krivokhizhina at the University of Louisville for their assistance with all the platelet aggregometry assay methods and results. Thank you to Gregg Shirk, Whitney Theis, and Alexis Hand of the Animal Core of the Diabetes and Obesity Center, as well as Dr. Timothy O'Toole and Aaron Puckett of the Flow Cytometry Core of the Diabetes and Obesity Center at the University of Louisville for their assistance with animal exposures and flow cytometry analyses. Thank you to my fellow colleagues and staff members of the Conklin laboratory (Jordan Lynch, Lexiao Jin, Alexandra Lipinski, Ganapathy Jagatheesan, and Luping Guo) for their training, advice, and assistance in the lab. In addition, special thanks to my committee members for their contributions to my project. Finally, I want to acknowledge the University of Louisville Department of Pharmacology \& Toxicology for allowing me to study at this university. 


\section{DEDICATION}

This thesis is dedicated to my mother, Angela Richardson, and also to my former undergraduate research mentor, Dr. Stephen G. Tajc. Mom, you are very reason why I chose to pursue this profession. I most certainly would not have the motivation and the courage to continue if it were not for you. Dr. Tajc, being a graduate student would not have been made possible without serving as your student. I am eternally grateful. Thank you both! 


\section{ABSTRACT \\ TOBACCO-DERIVED ALDEHYDES: PLATELET ACTIVATION, THROMBOSIS, AND THE ROLE OF TRPA1 \\ Andre Dwyane Richardson \\ November 12, 2019}

Cigarette smoking is the single largest risk factor for cardiovascular disease (CVD) pathophysiology. Numerous researchers have shown potential associations between aldehydes in tobacco-derived aerosols from mainstream cigarette smoke (MCS) or electronic cigarettes (e-cigs) and their cardiotoxicity by damaging blood vessel endothelium. The severity of exposure to these toxicants can furthermore lead to adverse cardiovascular outcomes such as myocardial infarctions, stroke, coronary and peripheral artery disease, or atherosclerosis due to blood clots, a pro-thrombotic event. However, the mechanisms by which levels of harmful and potentially harmful constituents (HPHCs) such as aldehydes induce thrombosis are not well-known. Of specific interest, evidence has shown that smoke exposure enhances platelet sensitivity and activation. Thus, the purpose of this project is to examine the effects of exposure to MCS, e-cigs, as well as their constituent saturated and unsaturated aldehydes, and flavoring additives on platelet activation as a marker of thrombosis. 
TABLE OF CONTENTS

PAGE

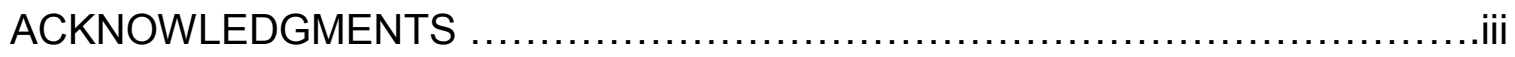

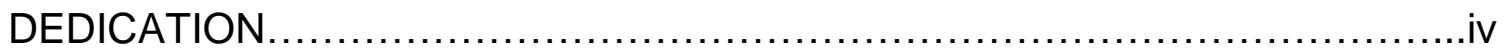

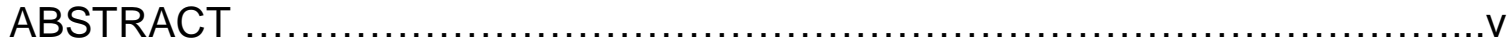

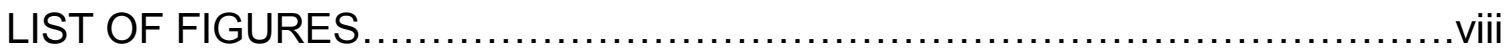

CHAPTER 1: INTRODUCTION.................................................

1.A. Cardiovascular Disease \& Tobacco Smoking..........................

1.B. The Prevalence of Electronic Cigarettes............................2

1.C. Toxicity of Tobacco-Derived Aldehydes and Flavors...................4

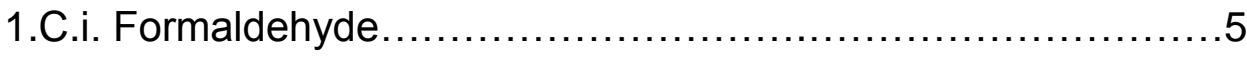

1.C.ii. Acetaldehyde............................................ 5

1.C.ii. Acrolein...................................................... 5

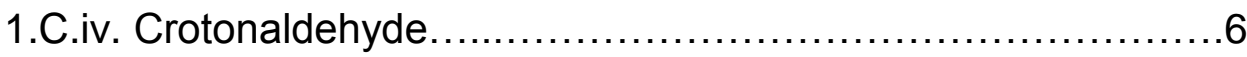

1.C.v. E-Cig Flavoring Additives.................................. 7

1.D. Pathophysiology of Platelet Activation/ Thrombosis...................8

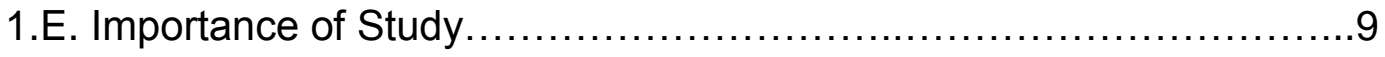


1.F. Summary

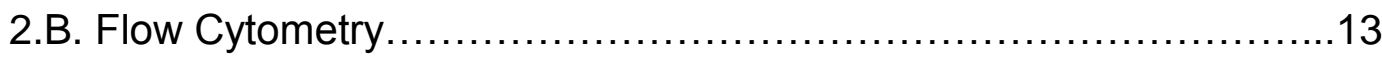

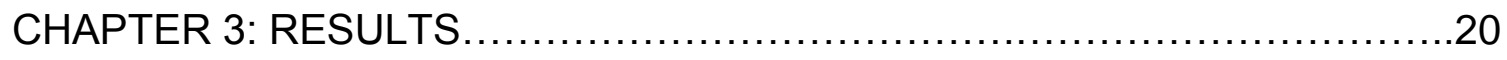

CHAPTER 4: DISCUSSION \& CONCLUSION .................................47

4A. Platelet Aggregometry Data Interpretation..........................47

4.B. Flow Cytometry Data Interpretation...............................50

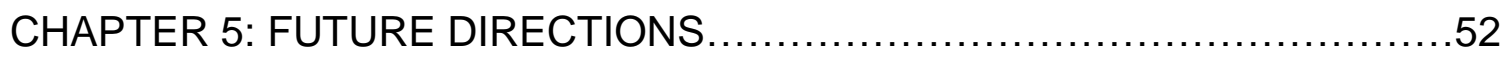

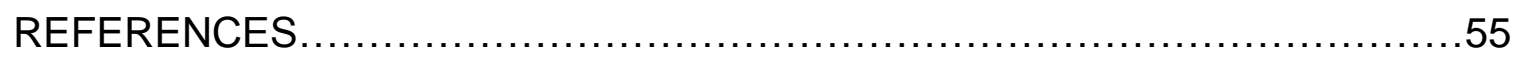

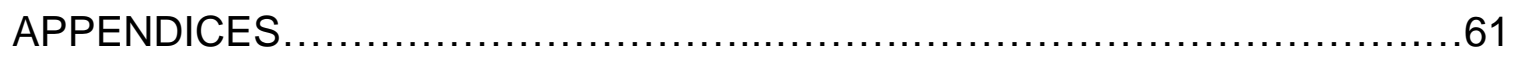

Abbreviations ............................................................

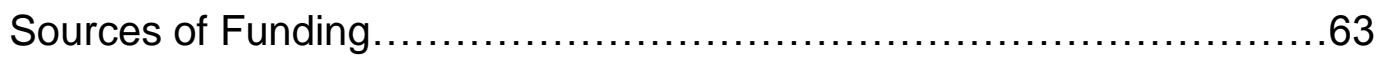

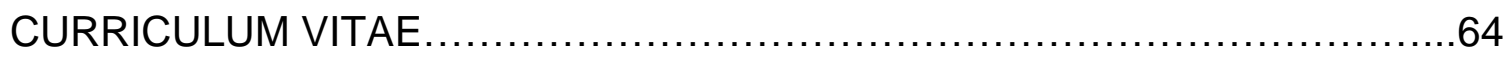




\section{LIST OF FIGURES}

\section{FIGURE}

PAGE

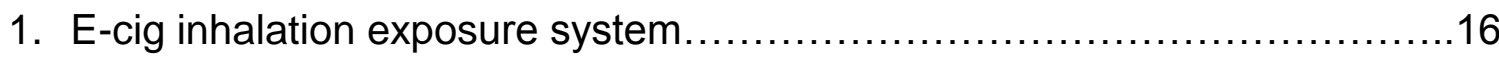

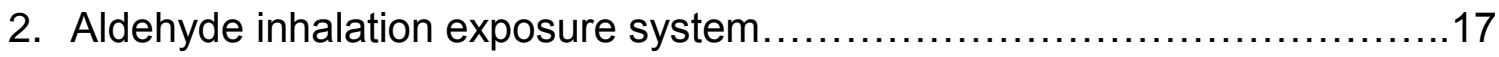

3. Concentration-dependent effects of vegetable glycerin-derived acrolein on

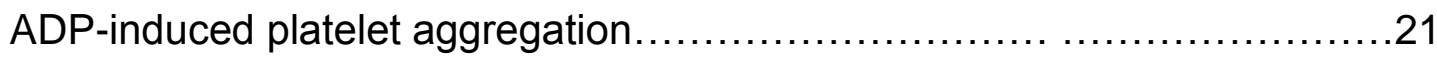

4. Concentration-dependent effects of clove oil-derived eugenol on ADPinduced platelet aggregation 23

5. Concentration-dependent effects of cinnamon-derived cinnamaldehyde on

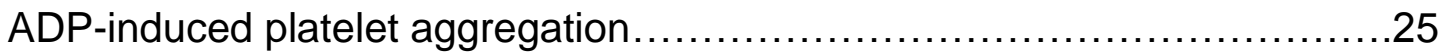

6. Effect of vanilla-derived vanillin on ADP-induced platelet aggregation.........26

7. Effect of mint-derived menthol on ADP-induced platelet aggregation.........28

8. Effects of acute MCS exposure on PLAs in male mice .......................30

9. Effects of acute e-cig exposure on PLAs in male mice .......................32

10. Effects of acute formaldehyde (2 ppm) exposure on PLAs in male mice......34

11. Effects of acute formaldehyde (5 ppm) exposure on PLAs in male mice......35

12. Effects of acute (2-wk) formaldehyde ( $5 \mathrm{ppm}$ ) exposure on PLAs in male mice. 36

13. Effects of acute formaldehyde (2 ppm) exposure on PLAs in female mice...38 14. Effects of acute formaldehyde (5 ppm) exposure on PLAs in female mice...39 
15. Effects of acute acetaldehyde (5 ppm) exposure on PLAs in male mice.....41

16. Effects of acute (2-wk) acetaldehyde (5 ppm) exposure on PLAs in male

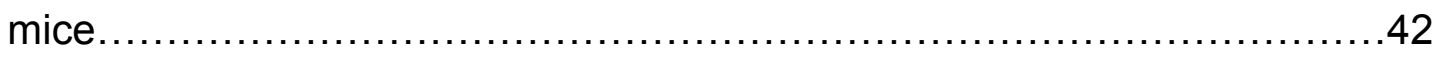

17. Effects of acute acetaldehyde (5 ppm) exposure on PLAs in female mice....44

18. Effects of acute or chronic crotonaldehyde exposure in male mice.............46 


\section{CHAPTER 1:}

\section{INTRODUCTION}

\section{A. Cardiovascular Disease (CVD) \& Tobacco Smoking}

Cardiovascular diseases are a collective of pathological changes involving the structure and function of the heart and/or the blood vessels [1], and CVD are a major public health concern. Coronary heart disease (CHD), a type of CVD, is most prominently caused by atherosclerosis that occurs due to cholesterol and fatty deposits building along the arterial wall [2, 3]. This action causes plaque accumulation, narrowing of arteries leading to hypertension [1, 3], and thus increasing the risk of atherosclerosis, myocardial infarction (MI), and stroke. Also regarded as the leading death causing disease in the U.S. as well as worldwide [4], CVD claims more lives each year than all forms of cancer and chronic respiratory diseases combined and also accounts for approximately 610,000 related deaths every year, which is one out of every four deaths. Related to public health, the costs associated with CVD total more than $\$ 316$ billion in health expenditures and lost productivity and is expected to rise to $>\$ 1$ trillion dollars by the year 2030 [4]. These statistics demonstrate the severity of CVD as both significant health and financial concerns for the public. 
As noted by the Centers for Disease Control and Prevention (CDC) and the American Heart Association (AHA), smoking harms nearly every organ of the human body, causing many diseases, and significantly reducing an individual's overall health with chronic use as well as to those around them due to secondhand smoke exposure [5-8]. Smoking is reported as the leading preventable cause of severe illnesses and premature death in the U.S. $[9,10]$. Smoking contributes to more than 440,000 deaths each year, accounting for $30 \%$ of CVD-related deaths in the U.S.

Tobacco smoking exacerbates plaque build-up along blood vessel walls [11] as a result of the tobacco-derived chemical constituents causing hypercoagulability in the blood and platelets to activate. This leads to formation of a thrombus within the vessels. This pathophysiologic outcome manifests in the form of Ml, stroke, and thrombosis. Moreover, stroke alone is characterized as an impairment of cerebral cognition and function due to lack of blood reaching the brain [12]. It has been reported that current smokers are at a significantly higher risk of stroke compared with individuals who have never smoked or are former smokers [13-16].

\section{B. The Prevalence of Electronic Cigarettes}

Smoking devices such as electronic cigarettes (e-cigs) impose a new threat to public health and have been linked to increased risk of developing CVD-

related illnesses $[17,18]$. In the U.S., the development of "next-generation" e-cigs in 2007 has prompted a completely different public health burden. Conventional 
tobacco usage was at a decline, but an increased use of e-cigs was observed with an initial claim that these were a healthier substitute $[19,20]$. Compared with conventional tobacco products, e-cigs are considered electronic nicotine delivery systems (ENDS) since these do not typically contain tobacco [21]. These products are marketed specifically towards youth and young adults. The concern, however, is that by using these products, the potential for renormalizing use of conventional tobacco products is increased as well as CVD-risk [19]. The common misconception is that e-cigs are less toxic because they contain far less non-carcinogenic ingredients and do not produce highly toxic aerosols compared with those of conventional cigarettes [22]. Conventional tobacco cigarettes contain hundreds of ingredients (e.g. nicotine and cardiotoxic heavy metals), and during combustion, the smoke that is generated consists of a complex mixture of more than 7,000 toxic chemical constituents (e.g. aldehydes, polycyclic aromatic hydrocarbons, carbon monoxide, oxidants, ammonia, and tar) [23]. Approximately 70 of the known constituents of these products are known carcinogens and/or are poisonous [23]. On the other hand, e-cigs contain eliquids with the following ingredients: propylene glycol (PG), vegetable glycerin (VG), nicotine, and various flavoring additives [24]. Around the time e-cigs were introduced, these e-liquids were thought to be nontoxic because either they did not contain toxic byproducts or they did not produce these toxins at levels near those present in or derived from tobacco combustion [25-27]. However, Sassano et al. showed that chemicals in e-liquids do have toxic effects by negatively 
affecting cell viability [27]. Additionally, nicotine is an addictive substance with severe health risks $[28,29]$.

\section{C. Toxicity of Tobacco-Derived Aldehydes and Flavors}

In a conventional tobacco cigarette, smoke generated by combustion contains toxic reactive aldehydes, specifically formaldehyde, acetaldehyde, acrolein, and crotonaldehyde. These are also known as harmful or potentially harmful constituents (HPHCs) [30]. On the other hand, when taking a puff from an e-cig, the e-liquids are then heated and generate an aerosol containing the same toxic reactive aldehydes as a result of a thermal dehydration reaction of the e-liquids [31]. Although acrolein and crotonaldehyde are not typically produced in e-cig aerosols, or produced at much lower levels compared with conventional tobacco smoke, there are proposed mechanisms by which PG/VG produces these unsaturated aldehydes as well [32]. VG produces acrolein, the simplest unsaturated aldehyde [32, 33]. PG generates saturated aldehydes such as formaldehyde, acetaldehyde, and propionaldehyde [32, 33]. Varying concentrations of these aldehydes are generated depending on the e-cig battery voltage [31, 34]. Furthermore, the various concentrations of aldehydes in e-cig aerosols are associated with a number of cardiovascular risks such as cardiac oxidative stress, DNA damage in bone marrow, increased platelet counts, and increased blood coagulation via platelet activation [35]. Acrolein, a common air pollutant, specifically has certainly been associated with increased CVD-risk [36, 37] and has been shown to increase thrombosis activate hemostasis via platelet 
activation [38], promote platelet-leukocyte aggregate formation and also forms adducts with platelets [38], though the mechanism is unclear. Although many health implications have been discussed concerning aldehydes derived from ecig vaping, there is not a clear, defined relationship between the toxic aldehydes and the risk these impose on CVD.

\section{C.i. Formaldehyde:}

Formaldehyde is the simplest aldehyde and is gaseous at room temperature; it is colorless with a pungent, irritating odor. According to the National Toxicology Program (NTP), formaldehyde is a known human carcinogen [39]. In terms of the cardiotoxic effects that are associated with formaldehyde exposure, it has been shown that high levels of formaldehyde induce vasopressor effects in anesthetized rats, or an increase in blood pressure as a result of a blood vessel undergoing contraction [40]. Conversely, lower levels of formaldehyde in rats result in hypotension [40].

\section{C.ii. Acetaldehyde:}

According to the NTP, acetaldehyde is a reasonably anticipated human carcinogen [41]. It has also been shown that acetaldehyde induces hypertension at high concentrations $(\geq 3.0 \mu \mathrm{g} / \mathrm{mL})$ in inhalation-exposed rats [42]. Similar results are observed when acetaldehyde is administered via intraperitoneal injection $(5-20 \mathrm{mg} / \mathrm{kg})$ with a decrease in heart rate [43-45].

\section{C.iii. Acrolein:}


Acrolein is a well-researched environmental toxicant and air pollutant which is generated as a result of burning and high temperature fumes [46, 47]. Acrolein, which can also be generated from VG degradation, is an $\alpha, \beta-$ unsaturated aldehyde, a known eye irritant, a respiratory and cardiovascular toxicant [46], and a major constituent of cigarette smoke [48]. Acrolein also induces vasopressor effects as demonstrated by Egle et al. 1974 in their study of intravenously-injected rats. While acrolein up to $0.25 \mathrm{mg} / \mathrm{kg}$ caused rapid hypertension [40], hypotension resulted from exposure at higher levels $(>0.25$ $\mathrm{mg} / \mathrm{kg}$ ) [40]. Exposure to acrolein via inhalation exposure also causes high blood pressure [40].

\section{C.iv. Crotonaldehyde:}

Crotonaldehyde is an $\alpha, \beta$-unsaturated aldehyde with a pungent, suffocating odor. Inhaled crotonaldehyde is toxic at low concentrations and causes irritation within the upper respiratory tract [49]. The Occupational Safety and Health Administration (OHSA) imposed a 2 ppm exposure limit to crotonaldehyde over an eight-hour workshift, but levels between $0.035 \mathrm{ppm}$ and $0.12 \mathrm{ppm}$ induce toxicity [50]. Although much remains unknown about the cardiotoxicity associated with crotonaldehyde exposures, we hypothesize that this compound could potentially induce vasopressor effects in a similar fashion as acrolein due to their similarities in their chemical structures.

For the purpose of this research, we will study formaldehyde, acetaldehyde, acrolein, and crotonaldehyde as these are the foremost toxic aldehydes present in tobacco and e-cig aerosols, and thus, may contribute to 
CVD-risk and noncancerous pulmonary disease. In our preliminary studies, we tested the effects of aldehyde exposure on platelet aggregation ex vivo as well as on platelet-leukocyte aggregate (PLA) formation in vivo.

\section{C.v. E-Cig Flavoring Additives:}

Today, the craze surrounding the e-cig market is the development and usage of flavorings. A variety of flavorings such as clove oil, cinnamon, vanilla, and mint allow e-cigs users to choose a desired sweetener for consumption. When heated using an e-cig, the chemical products (e.g. eugenol, cinnamaldehyde, vanillin, and menthol) may exacerbate CVD-risk [33]. This alone creates new alarms in that flavorings may contribute to adverse cardiovascular outcomes. A study published in 2018 revealed a remarkable finding that in fact nine flavoring products induce cardiotoxicity via endothelial cell dysfunction [51]. Fetterman et al. exposed human aortic endothelial cells to nine different flavoring compounds and found that these flavors induced dysfunction to the endothelium via cell death, oxidative stress, increased inflammation, and decreased nitric oxide (NO) production [51]. NO is well known to inhibit platelet activation [52-55], suggesting if NO is diminished due to flavoring exposure, the likelihood of platelet activation is significantly increased [56]. However, this idea that flavors induce platelet activation has yet to be fully investigated. In our preliminary study, we tested the effects of e-cig flavorings on adenosine diphosphate (ADP)-induced biphasic platelet aggregation ex vivo (see Materials \& Methods). 


\section{D. Pathophysiology of Platelet Activation/Thrombosis}

Platelets are small (2-3 $\mu \mathrm{m}$ in diameter) circulating fragments of megakaryocytes in the blood that play an important role in hemostasis, thrombosis, and inflammation [57]. Platelets aid in maintaining vascular integrity within an injured blood vessel via forming adducts with leukocytes, thus creating clots $[57,58]$. Quiescent platelets circulate throughout the vasculature until recruited to sites of vascular injury or damage, where they become activated [57]. Once activated, platelets undergo an initial shape change and secrete their $\alpha$ granule and dense granule contents via exocytosis or granule secretion. When this occurs, a number of catecholamines (e.g. adenosine diphosphate (ADP), adenosine triphosphate (ATP), serotonin, histamine, and calcium [59]) are released into circulation and bind to surface receptors of other nearby platelets [60]. This initiates a cascade of signaling mechanisms, platelet activation, and aggregation ultimately leading to formation of a platelet plug, preventing further bleeding and/or hemorrhaging.

Thrombosis is described as the formation of a thrombus, or clot. Deep vein thrombosis (DVT), venous thromboembolisms, and pulmonary embolisms are all influenced by platelet aggregates. It is well known that smoking is a risk factor for the development of thrombosis. As demonstrated by Morris et al. and other investigators, traditional cigarettes and e-cig smoking strongly impacts the turnover, structure, activation, and function of platelets [17,61]. Each of these pro-thrombotic actions contribute to CVD-related morbidity and mortality. 


\section{E. Importance of Study}

Hypothesis: Tobacco-derived constituents induce platelet activation as observed by potentiated biphasic platelet aggregation ex vivo and increased platelet-leukocyte aggregate (PLA) formation in vivo.

Aim 1: Test the concentration-dependent influence of tobacco-derived acrolein and flavorings on phase-specific ADP-induced platelet aggregation.

Aim 2: Examine the level- and duration-dependent effects of exposure to mainstream cigarette smoke (MCS), e-cig aerosol, and aldehydes on PLA formation.

Exposure to acrolein activates hemostasis and pro-thrombotic events via platelet activation. Exposure to acrolein from smoking induces the formation of PLAs and also forms adducts with the platelets themselves [38], though the mechanism is unclear. Thus, we aim to determine the specific contribution of aldehydes and flavorings in smoking products to platelet activation in order to better define the relationship between these toxins and CVD-risk. Platelets undergo a cascade of events following activation (e.g. adhesion, aggregation, and complex formation with leukocytes leading to platelet plug formation), and these could all be influenced by interaction with inhaled tobacco constituents. Platelet adhesion is the first action of platelet activation upon blood vessel injury involving platelet surface receptor protein interactions with collagen in the subendothelium [62]. Platelet aggregation is the second action of platelets following release of granules and catecholamines in order to form clots [63], addressed in the first specific aim. PLAs are those complexes formed with leukocytes upon 
adhesion and aggregation at the site of blood vessel injury [38, 58, 64],

addressed in the second specific aim. Each specific aim is significant in that they will help to better define the mechanism of tobacco smoke-induced cardiovascular toxicity, specifically regarding platelet activation. Furthermore, we aim to determine the levels of aldehyde- and flavor-containing aerosols capable of inducing unwarranted thrombotic events.

\section{F. SUMMARY}

We are proposing that cigarette smoke and vaping exposure induces cardiotoxicity via platelet activation. Taken together, the results of this proposed preliminary research will help our understanding of these tobacco products and how they potentially threaten cardiovascular health. Since the development of ecigs, there is an urgent need to address the potential cardiotoxic outcomes that may result from using these products. Many researchers have addressed carcinogenic and pulmonary outcomes from using e-cigs [65-68], however, more research is needed to gain knowledge about the cardiovascular-related outcomes, adding to the significance and impact of this research. 


\section{CHAPTER 2:}

\section{MATERIALS \& METHODS}

\section{A. ADP-induced Platelet Aggregation in vitro via Platelet Aggregometry Assay:}

The dynamism of platelets has long been studied via a number of different platelet function assays and methodologies [69]. The platelet aggregometry assay is the most widely accepted, gold standard platelet function assay that utilizes human platelet rich plasma (PRP) of whole blood. This method measures the ability of different stimuli to induce platelet-platelet aggregation ex vivo.

Using the ex vivo platelet aggregometry assay, the direct effects of the various concentrations of acrolein and e-cig flavoring compounds on ADP-induced platelet aggregation were assessed. Human biorepository blood were collected in top citrate tubes. Human PRP was be obtained via centrifugation ( $180 \mathrm{xg}, 12 \mathrm{~min}$ ) of whole blood for use in this assay. A ChronoLog aggregometer was used to measure aggregation photometrically post-ADP induction over five minutes. Fifty microliters of PRP were used to obtain a platelet count. The remaining blood was centrifuged again for 20 minutes at $1,300 \mathrm{xg}$ in order to obtain the platelet poor plasma (PPP) used as a reference sample in each experiment. Additionally, we

wanted the platelet concentration of PRP to be $3.00 \times 10^{8} \mathrm{plt} / \mathrm{mL}$. From the platelet 
counts, if the concentration was above this limit, we used the PPP to dilute the PRP using the equations below:

$$
\begin{gathered}
\frac{[\text { Initial Platelet in PRP] } x \text { Initial Volume of } P R P(m L)}{[\text { Desired Platelet in PRP }]} \\
=\text { Final Volume of } P R P(m L)
\end{gathered}
$$

Final Volume of PRP - Initial Volume of PRP

$$
=\text { Volume of PPP to add to PRP to obtain } 3.00 * 10^{8} \frac{\mathrm{plt}}{\mathrm{mL}}
$$

Following this procedure, varying concentrations $(10,30,300$, and $100 \mu \mathrm{M})$ of acrolein along with $10,25,50$, and $100 \mu \mathrm{M}$ concentrations of e-cig flavoring additives (eugenol, cinnamaldehyde, vanillin, and menthol) were tested to observe their effects on ADP-induced platelet aggregation using the aggregometer. Three hundred fifty microliter aliquots of PRP were placed into sample cuvettes within each of the four channels of the aggregometer and incubated for five minutes at $37 \stackrel{\circ}{\mathrm{C}}$ with continuous stirring at $1,000 \mathrm{rpm}$. Next in the test/control run, the aggregation response of the platelets with ADP $(2.5$ or $10 \mu \mathrm{M})$ were observed.

ADP was added to each sample, and we monitored and calculated the biphasic aggregation responses as phase 1 and phase 2 for an additional five minutes. Again, at resting state, our platelets were incubating with our 
constituent/chemical of choice for five minutes. Once ADP was added, it initiated a shape change followed by the phase 1 response solely due the stimulant. During phase 1 , the alpha and dense granules are secreting, and the secondary response is being amplified due to other platelets becoming activated and starting to aggregate together, which is the phase 2 response. We recorded total aggregation, phase 1 and phase 2 as percentages using the equation below.

Total Aggregation (\%) = Phase 1 Aggregation (\%) + Phase 2 Aggregation (\%)

In each of the following sample runs, each channel contained either ADP alone (positive control), ADP with acrolein, or ADP with an e-cig flavorant. We hypothesized that the compounds in question would enhance the sensitivity of the platelets directly.

Statistical Analysis:

Data analysis was performed using a paired Student's t-test in order to evaluate and compare differences in the mean percent responses of total, phase 1, and phase 2 aggregation of acrolein or flavorings with respect to control (ADP-only). Statistical significance was accepted at $p<0.05$.

\section{B. Platelet-Leukocyte Aggregates (PLA) in vivo via Flow Cytometry:}

\section{B.i. Mice Inhalation Exposure System:}


As described by Conklin et al. 2017 [70], we obtained C57BL/6J male and female mice from Jackson Laboratories and used them at 12 weeks of age. The mice were housed under pathogen-free conditions in the University of Louisville vivarium under controlled temperature and $12 \mathrm{~h}$ light: $12 \mathrm{~h}$ dark cycle. For the exposure system, the mice were exposed to either HEPA-filtered air (control) or aldehyde (specified aerosol, concentration, and duration of exposure) using a custom exposure system and certified permeation tubes as described by O'Toole et al. 2014 [71]. Immediately after completion of final exposure, the mice were anesthetized with sodium pentobarbital $(150 \mathrm{mg} / \mathrm{kg}$ ) followed by ventral thoracotomy and exsanguination via cardiac puncture for blood collection in EDTA (0.2 M; $20 \mu \mathrm{L}$ )-coated syringes (22G in diameter). The blood was transferred into in EDTA coated microcentrifuge tubes and kept on ice until aliquotted for plasma, CBC, or for preparation of flow cytometry analysis. We also performed $\mathrm{CBC}$ and looked at platelet numbers and platelet volume.

\section{B.ii. Mainstream Cigarette Smoke and E-Cig Aerosol:}

Adult C57BL/6 male mice underwent an acute (6h/d, 4d) whole body exposure to HEPA-filtered air (control), mainstream cigarette smoke (MCS; 3R4F reference cigarettes; $12 \mathrm{cig} / \mathrm{d}$ ) or e-cig aerosol (blu+; $6 \mathrm{~h} / \mathrm{d}, 4 \mathrm{~d})$ via inhalation (see Figure 1). As detailed by Conklin et al. 2018, a software-controlled (FlexiWare) cigarette-smoking robot (CSR) (SCI-REQ; Montreal, CAN) system was used to generated cigarette smoke aerosols from KY Reference cigarettes (3R4F) and e-cig cartridges (blu®) [32]. Our MCS exposure followed the International Standard of Organization (ISO) protocol (i.e. $2 \mathrm{~s}$ puff, $35 \mathrm{~mL}$ puff, 1 
puff/min, 9 puffs/cigarette, 2 cigarettes/h) [32]. Our e-cig exposure consisted of 13 e-cig sessions per $4 \mathrm{~h}$ exposure. Each session (9 min; same duration as 1 cigarette) had 18 puffs ( $4 \mathrm{~s}$ puff, $91 \mathrm{~mL}$ puff, 2 puffs $/ \mathrm{min}$ ) [32]. After the final exposure, the mice were immediately euthanized and peripheral blood collected and used in flow cytometry to detect CD45 $/$ CD41+ PLAs.

\section{B.iii. Aldehyde exposures:}

C57BL/6 male and female mice were placed into a sealed chamber which allowed for an aldehyde-like atmosphere for the mice to inhale during a continuous exposure of aldehyde for a specified duration (see Figure 2). Control mice were placed into similar chambers in which they were exposed to HEPAfiltered air.

\section{B.iv. Statistical Analysis:}

Data are reported as mean \pm standard error. For statistical comparison between two groups, the Mann-Whitney U test was used. Significance was accepted where $p<0.05$. 


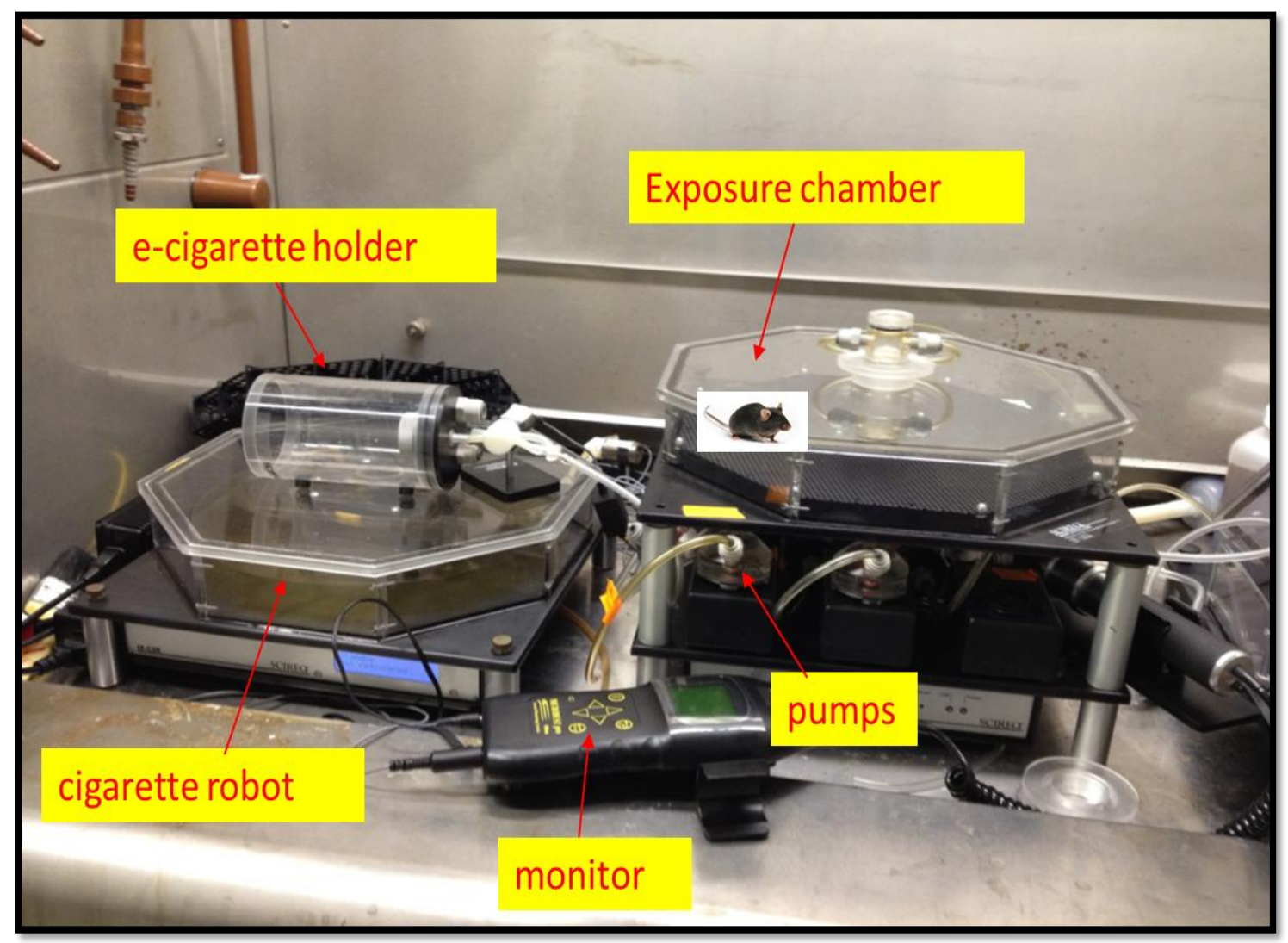

Figure 1. E-cig inhalation exposure system. The pump draws out vapor from the e-cig and transfers the vapor into the exposure chamber in which the C57BL/6 male mice are contained during exposure. The MCS exposure has a similar set up for transferring smoke to mice in the exposure chamber, but MCS exposure involves 12 3R4F reference tobacco cigarettes following ISO protocol (i.e., $2 \mathrm{~s}$ puff, $35 \mathrm{~mL}$ puff, $1 \mathrm{puff} / \mathrm{min}, 9 \mathrm{puffs} / \mathrm{cigarette} ; 2$ cigarettes $/ \mathrm{h}$ [32]. The total suspended particulate (TSP) matter was monitored in real time with an inline infrared forward scattering monitor (MicroDust Pro; Casella CEL Ltd., Bedford, UK). 

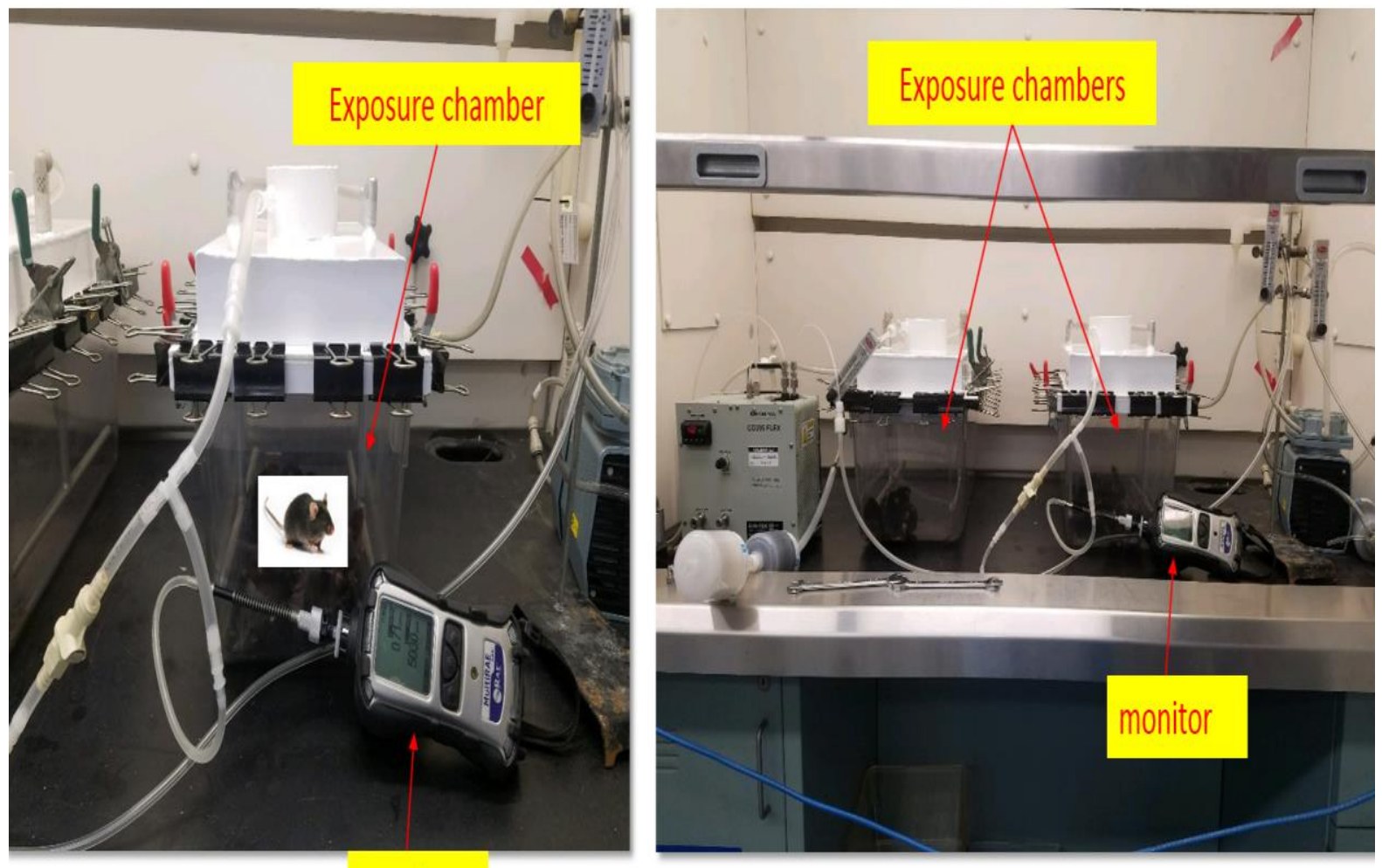

monitor

Figure 2. Aldehyde inhalation exposure system. C57BL/6 male or female mice are placed inside a sealed exposure chamber. Steady, continuous $6 \mathrm{~h}$ flow of aldehyde gas is pumped via certified permeation tubes (Kin-Tek; LaMarque, TX) into the chamber per specified duration in each study [71,72]. During exposure, aldehydes are monitored continuously with an in-line calibrated photoionization detector (PID; ppbRAEPlus, Rae Industries, Sunnyvale, CA) [72]. 


\section{B.v. Formaldehyde:}

Adult male and female C57BL/6 mice underwent an acute $(6 \mathrm{~h} / \mathrm{d}, 4 \mathrm{~d}$ or 2wk) exposure to HEPA-filtered air (control) or formaldehyde (2 or $5 \mathrm{ppm}$ ) via inhalation. After the final exposure, the mice were immediately euthanized and peripheral blood collected and used to detect CD45+/CD41+ PLAs by flow cytometry.

\section{B.vi. Acetaldehyde:}

Adult male and female C57BL/6 mice underwent an acute exposure (6 $\mathrm{h} / \mathrm{d}, 4 \mathrm{~d}$ or $2 \mathrm{wk}$ ) exposure to HEPA-filtered air (control) or acetaldehyde (5 ppm) via inhalation. After the final exposure, the mice were immediately euthanized and peripheral blood collected and used to detect CD45+/CD41+ PLAs by flow cytometry.

\section{B. vii. Crotonaldehyde:}

Adult male and female C57BL/6 mice underwent an acute $(6 \mathrm{~h} / \mathrm{d}, 4 \mathrm{~d})$ or chronic (12wk, 6h/d) exposure to HEPA-filtered air (control) or crotonaldehyde (1 ppm) via inhalation. After the final exposure, the mice were immediately euthanized and peripheral blood collected and used to detect CD45 $/ C D 41^{+}$ PLAs by flow cytometry.

Activated platelets not only bind to endothelium and to other platelets, but they also bind to leukocytes $[58,64,73]$. PLAs are one of the in vivo markers of thrombosis. As previously described by Sithu et al. [38], the PLAs were quantified as events double positive for CD41 (platelets) and CD45 (leukocytes) by flow 
cytometry. For this, 100 microliter aliquots of male or female mouse whole blood were diluted with $400 \mu \mathrm{L}$ of HEPES-Tyrodes solution before being fixed using $16 \%$ paraformaldehyde $(50 \mu \mathrm{L})$ at room temperature for 30 minutes. Red blood cells were then lysed by dilution with milliQ water $(2 \mathrm{~mL})$, and the lysed cells were collected by centrifugation at $400 \times \mathrm{g}$ for five min then decanted. The remaining cells were incubated $\left(4{ }^{\circ} \mathrm{C}\right)$ with $1 \%$ Fc Block $(5 \mu \mathrm{L})$ for 10 min before staining with FITC-labeled anti-CD41 and APC-labeled anti-CD11b or isotype matched negative controls (FITC IgG1 and APC IgG2b kappa) for additional 30 min. Stained cells were washed with HEPES-Tyrodes $(1 \mathrm{~mL})$ solution containing $1 \% \mathrm{BSA}$, centrifuged at $400 \times \mathrm{g}$ for five minutes and resuspended in HEPESTyrodes solution $(250 \mu \mathrm{L})$. A BD LSR Flow Cytometer (BD Biosciences; San Jose, CA) was used to analyze the stained cells, and 20,000 CD45+ events were collected from each sample. A FlowJo v10 (FlowJo, LLC) software was used to gate for our PLAs. We began with gating for our CD45+ leukocytes using side scatter. Then, the IgG negative control assisted in determining where to place the CD41+ platelet gate. Thus, our PLAs were identified in quadrant 2 (Q2). 


\section{CHAPTER 3:}

\section{RESULTS}

\section{A. Direct effect of acrolein on ADP-induced phase 1 and phase 2 aggregation ex vivo. The current study explores the biphasic platelet}

aggregation responses to concentration-dependent acrolein exposure. Sithu et al. completed a study in which mice were fed acrolein (1-5 mg/kg/day) for 1-3 days, and their blood collected and pooled to measure ADP-induced platelet aggregation. They found that acrolein augmented ADP-induced aggregation [74]. The present study solely explores direct exposure of acrolein to human platelets. Our data shows acrolein has no effect ADP-induced total aggregation, which has been previously published [75]. Furthermore, only low concentrations of acrolein (10 and $30 \mu \mathrm{M})$ induce a decrease in phase 1 and an increase in phase 2 aggregation (Figure 3). 

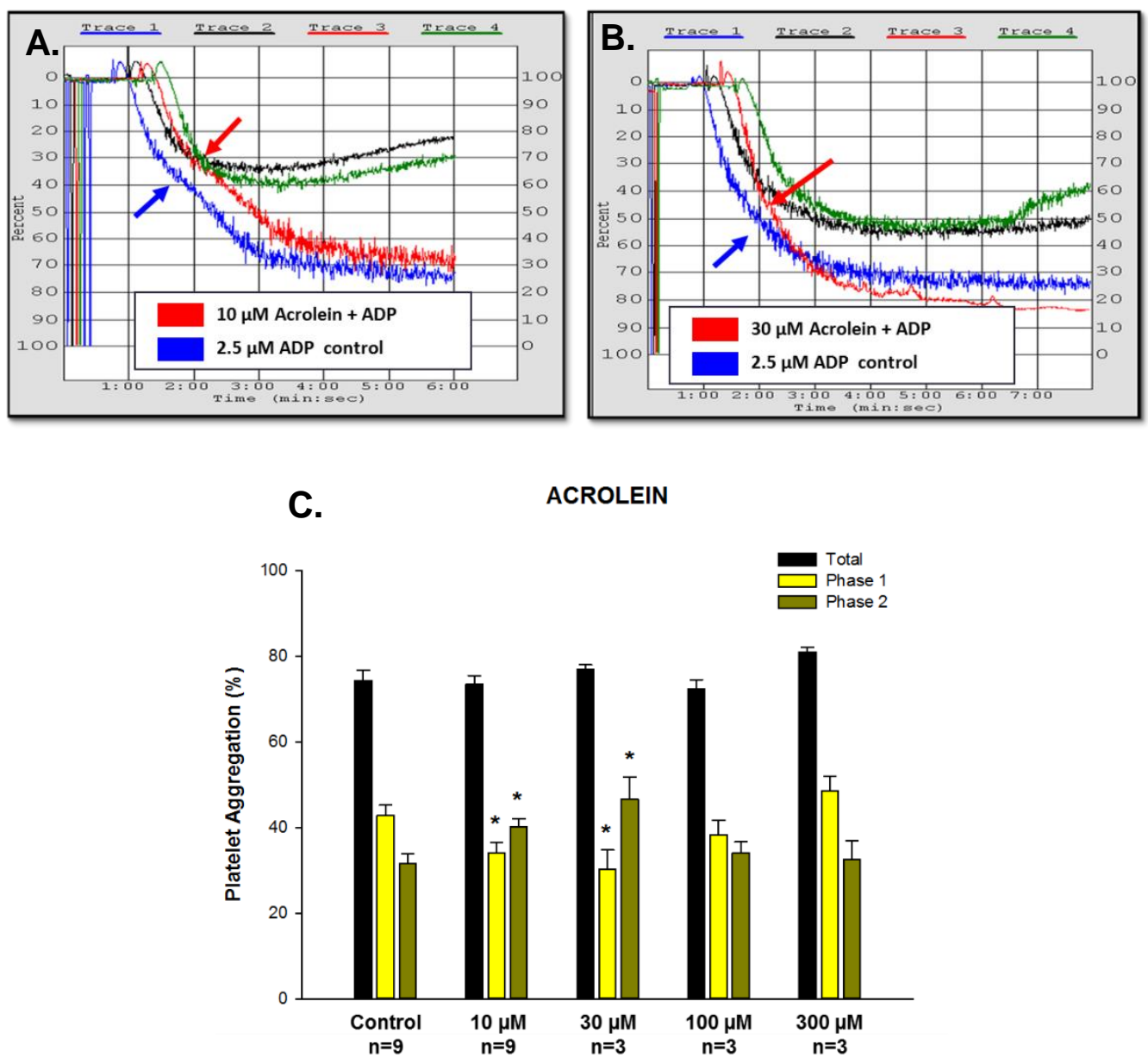

Figure 3. Concentration-dependent effects of vegetable glycerin-derived acrolein on ADP-induced platelet aggregation. A) Acrolein $(10 \mu \mathrm{M})$ and ADP $(2.5 \mu \mathrm{M})$ tested versus ADP-alone control; B) Acrolein $(30 \mu \mathrm{M})$ and ADP tested versus ADP-only control. Arrows indicate the inflection point between phase 1 and phase 2 aggregation. C) Summary data of concentration-dependent effects of acrolein on ADP-induced platelet aggregation. Using a paired Student's t-test, the percent responses of total, phase 1 , and phase 2 aggregation of acrolein were compared with respect to their control. Statistical significance was accepted where $p<0.05$. This study only found biphasic changes at $10 \mu \mathrm{M}$ and $30 \mu \mathrm{M}$ concentrations compared with control. 


\section{B. Direct effect of clove oil-derived eugenol on ADP-induced phase 1 and}

phase 2 platelet aggregation ex vivo. We are interested in how flavors from vaping may influence pro-thrombotic events. A study by Muthumalage et al. 2017 investigated respiratory outcomes associated with exposure to different e-cigderived flavoring compounds, without the presence of nicotine [76]. Though ingestion of these flavorings is potentially safe, the study revealed that consumption of flavors via inhalation is not recommended. We hypothesized that direct exposure to eugenol (clove oil) induces significant changes in biphasic platelet aggregation ex vivo. We found that eugenol exhibited antiplatelet/inhibitory responses at each concentration tested (Figure 4). 

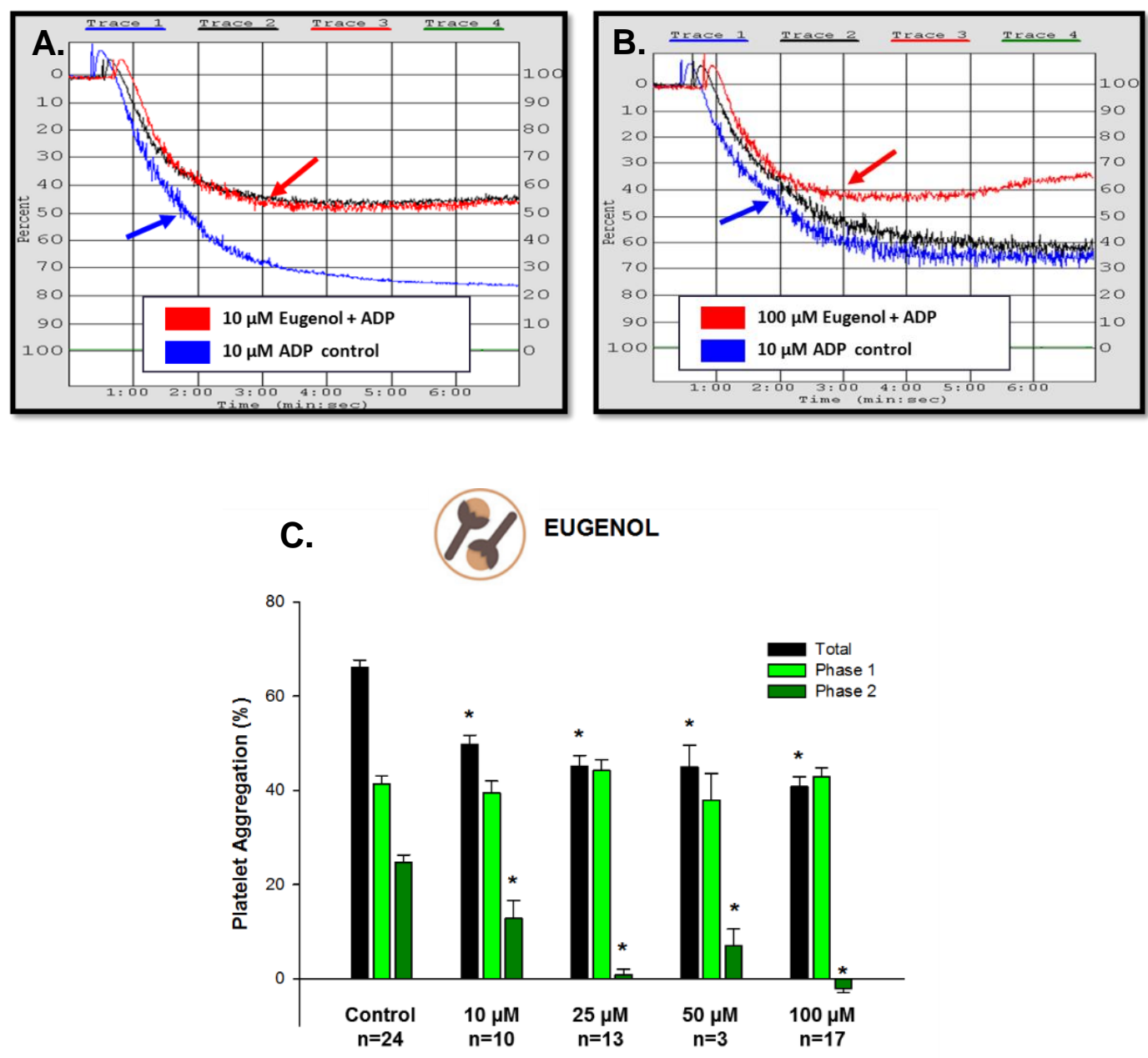

Figure 4. Concentration-dependent effects of clove oil-derived eugenol on ADPinduced platelet aggregation. A) Eugenol $(10 \mu \mathrm{M})$ and ADP $(10 \mu \mathrm{M})$ tested versus ADP-alone control; B) Eugenol ( $100 \mu \mathrm{M})$ and ADP tested versus ADP-only control. Arrows indicate the inflection point between phase 1 and phase 2 aggregation. $\mathbf{C}$ ) Summary data of concentration-dependent effects of eugenol on ADP-induced platelet aggregation. Using a paired Student's t-test, the percent responses of total, phase 1, and phase 2 aggregation of eugenol were compared with respect to their control. Statistical significance was accepted where $p<0.05$. This study found significant inhibition at each concentration compared with control. However, no change in phase 1 was observed. 
3.C. Direct effect of cinnamon- and vanilla-derived cinnamaldehyde and vanillin on ADP-induced phase 1 and phase 3 platelet aggregation ex vivo. Muthumalage et al. 2017 also found that e-cig-derived cinnamaldehyde and vanillin were the two most toxic compounds, causing both inflammatory and oxidative responses in vitro [76]. The present study investigates these two flavoring compounds known to induce some cardiovascular-related events. We hypothesized that direct exposure to eugenol (clove oil), cinnamaldehyde (cinnamon), vanillin (vanilla), or menthol (mint) induces significant changes in biphasic platelet aggregation ex vivo. We found that cinnamaldehyde (Figure 5) and vanillin (Figure 6) exerted no effects on ADP-induced biphasic platelet aggregation. 

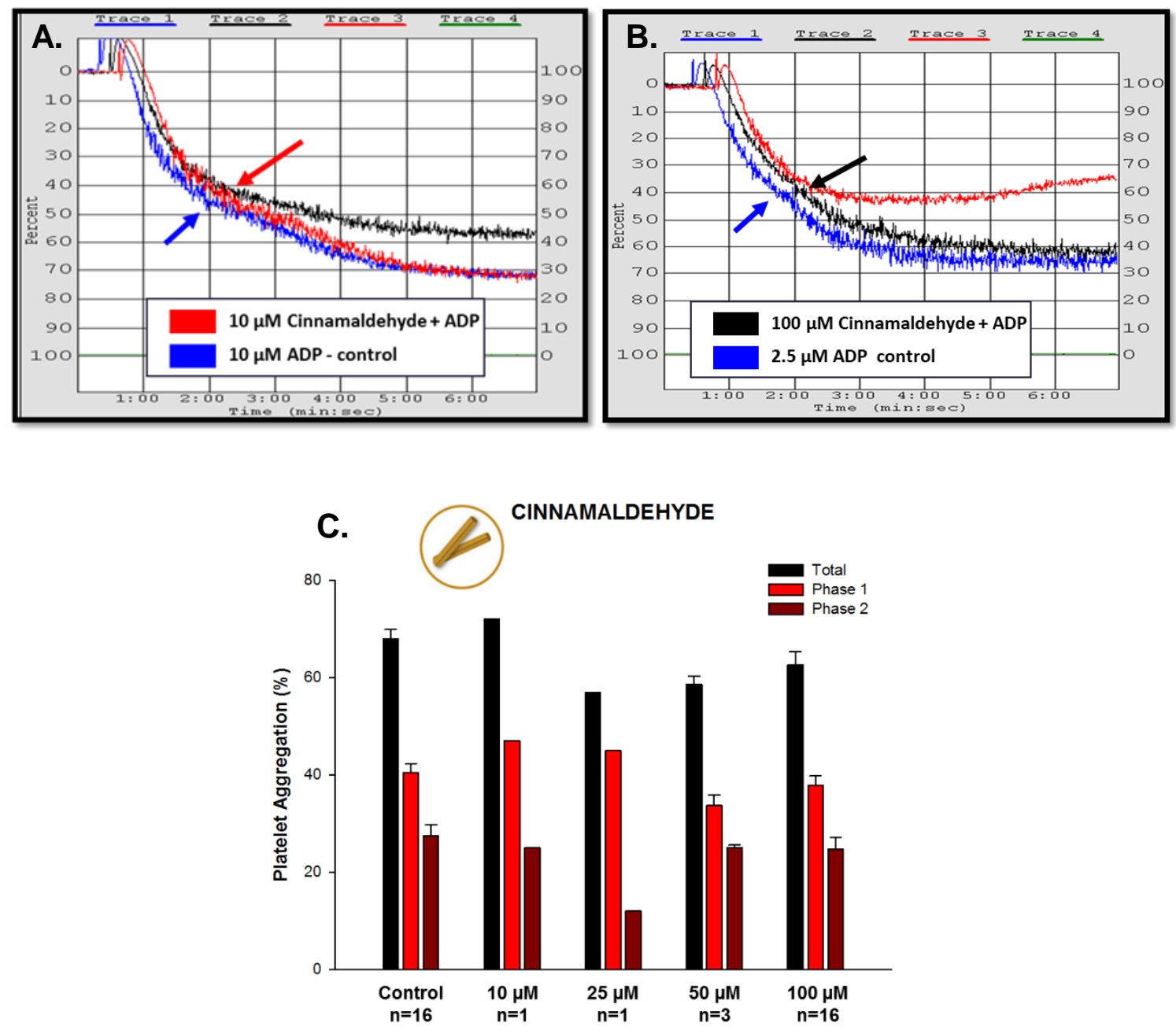

Figure 5. Concentration-dependent effects of cinnamon-derived cinnamaldehyde on ADP-induced platelet aggregation. A) Cinnamaldehyde $(10 \mu \mathrm{M})$ and ADP (10 $\mu \mathrm{M})$ tested versus ADP-alone control; B) Cinnamaldehyde $(100 \mu \mathrm{M})$ and ADP tested versus ADP-only control. Arrows indicate the inflection point between phase 1 and phase 2 aggregation. C) Summary data of concentration-dependent effects of cinnamaldehyde on ADP-induced platelet aggregation. Using a paired Student's t-test, the percent responses of total, phase 1, and phase 2 aggregation of cinnamaldehyde were compared with respect to their control. Statistical significance was accepted where $p<0.05$. No significant changes were detected. 
A.

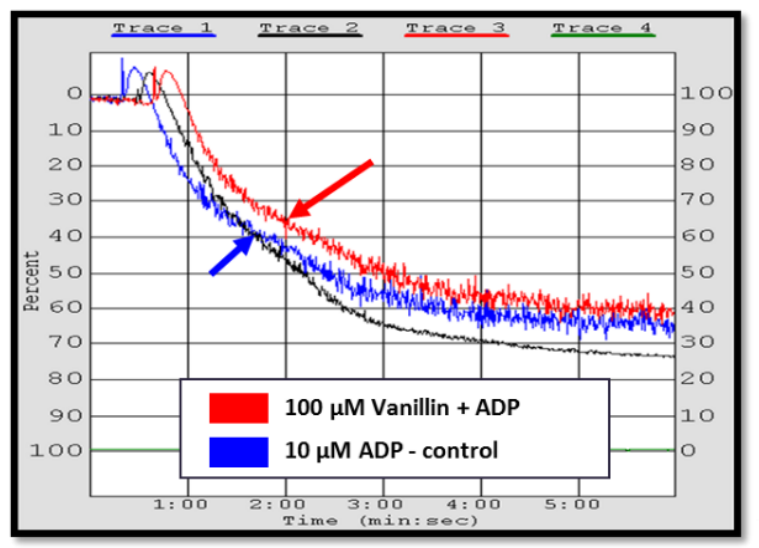

B.

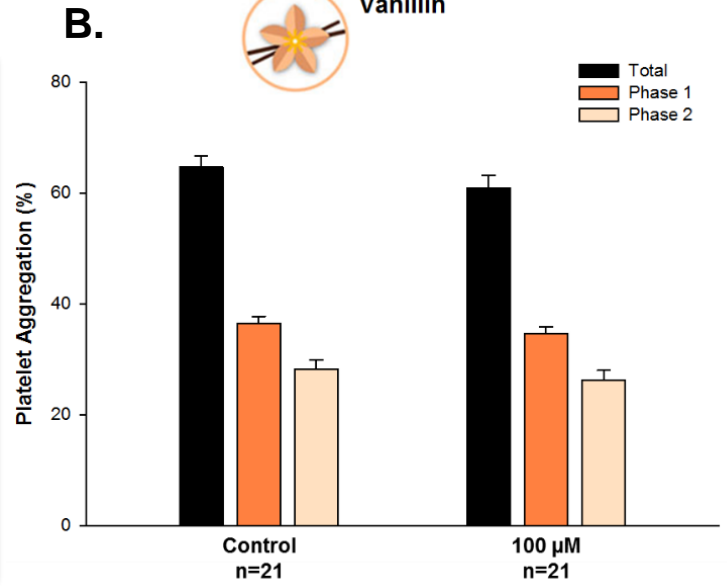

Figure 6. Effect of vanilla-derived vanillin on ADP-induced platelet aggregation. A) The representative curve indicating vanillin $(100 \mu \mathrm{M})$ and ADP $(10 \mu \mathrm{M})$ tested versus ADP-alone control. Arrows indicate the inflection point between phase 1 and phase 2 aggregation. B) Summary data of effect of vanillin on ADP-induced platelet aggregation. Using a paired Student's t-test, the percent responses of total, phase 1, and phase 2 aggregation of vanillin were compared with respect to their control. Statistical significance was accepted where $p<0.05$. No significant changes were detected. 
3.E. Direct effect of mint-derived menthol on ADP-induced phase 1 and phase 2 platelet aggregation. The present study investigates menthol flavoring, known to induce some cardiovascular-related events. Ciftçi et al. 2009 evaluated cardiovascular outcomes associated with menthol (mentholated) tobacco cigarettes in humans [77]. They found that mentholated cigarettes worsened cardiovascular outcomes compared with non-mentholated cigarettes as demonstrated by impaired ventricular diastolic function, exacerbated heart rate (101.2 bpm compared with $83 \mathrm{bpm}$ ), increased in systolic blood pressure (130.7 $\mathrm{mmHg}$ compared with $118.0 \mathrm{mmHg}$ ), and increased stiffness of the carotid artery (index of 5.7 compared with 2.2) [77]. We hypothesized that direct exposure to menthol induces significant changes in biphasic platelet aggregation ex vivo. We found that menthol exerted no effects on ADP-induced biphasic platelet aggregation (Figure 7). 
A.

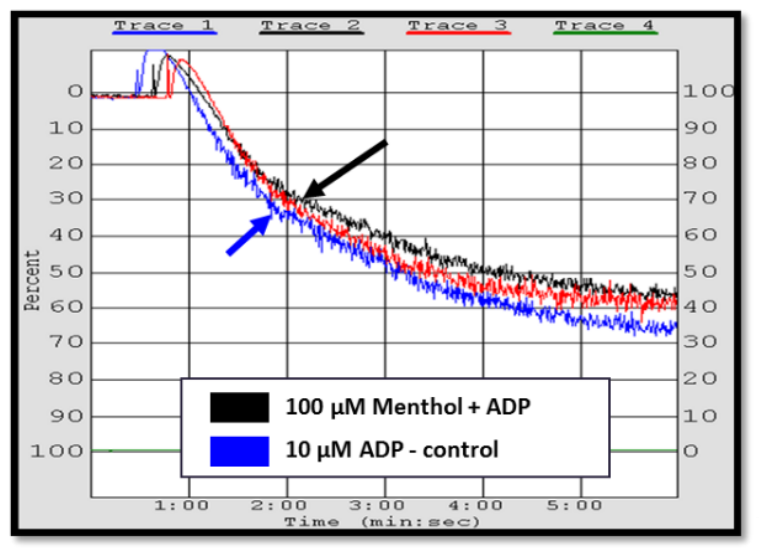

B.

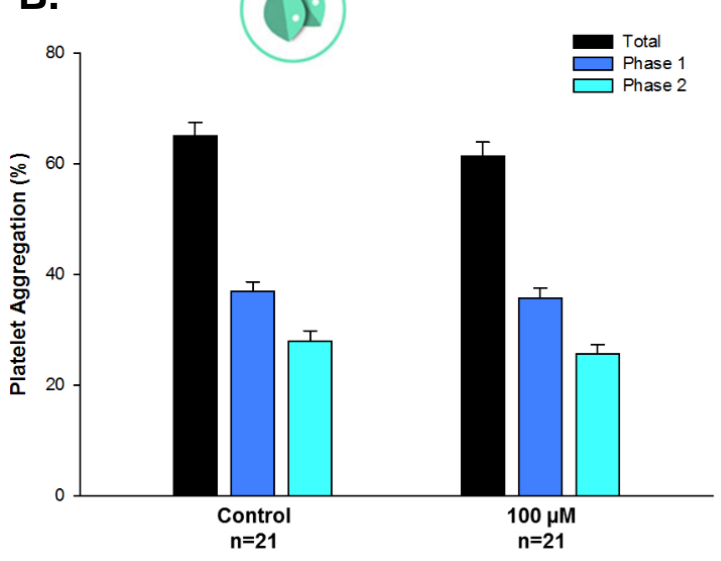

Figure 7. Effect of mint-derived menthol on ADP-induced platelet aggregation. . A) The representative curve indicating menthol $(100 \mu \mathrm{M})$ and ADP $(10 \mu \mathrm{M})$ tested versus ADP-alone control. Arrows indicate the inflection point between phase 1 and phase 2 aggregation. B) Summary data of effect of menthol on ADP-induced platelet aggregation. Using a paired Student's t-test, the percent responses of total, phase 1, and phase 2 aggregation of menthol were compared with respect to their control. Statistical significance was accepted where $p<0.05$. No significant changes were detected. 


\section{F. Effect of acute MCS exposure via inhalation on C57BL/6 male mice.}

Various physiological mechanisms have been proposed for tobacco smokeinduced CVD. Salahuddin et al. proposed that cigarette smoke is comprised of oxidant gases and toxic chemicals that inevitably release and activate free radicals that cause oxidative stress, increase inflammation, and decrease NO production [78]. As a result of these effects, platelet activation and thrombosis are more likely to occur. With this knowledge, we hypothesized that acute exposure to MCS will lead to platelet activation in vivo as measured by increased formation of PLAs. To test this hypothesis, C57BL/6 male mice were exposed to MCS (12 cigs/d, 4d) or HEPA-filtered air (control; 4d, 6h/d). Immediately after final exposure, the mice were euthanized and their peripheral blood was collected and prepared for flow cytometric analyses for identification and quantification of CD45 $/$ CD41+ PLAs. Our results indicate that acute exposure to MCS yielded a significant increase in PLA formation compared with air control (Figure 8). These data suggest that exposure to MCS causes platelet activation. 
A.i.

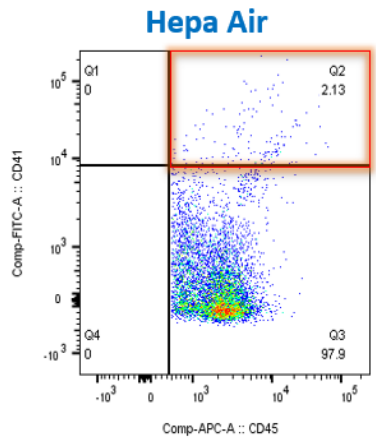

MCS

A.ii.

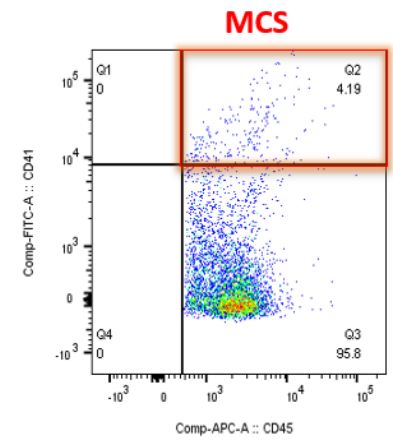

B. C57BL6 Male Mice: 4-d MCS 12-cigs/day ( $n=5,5)$

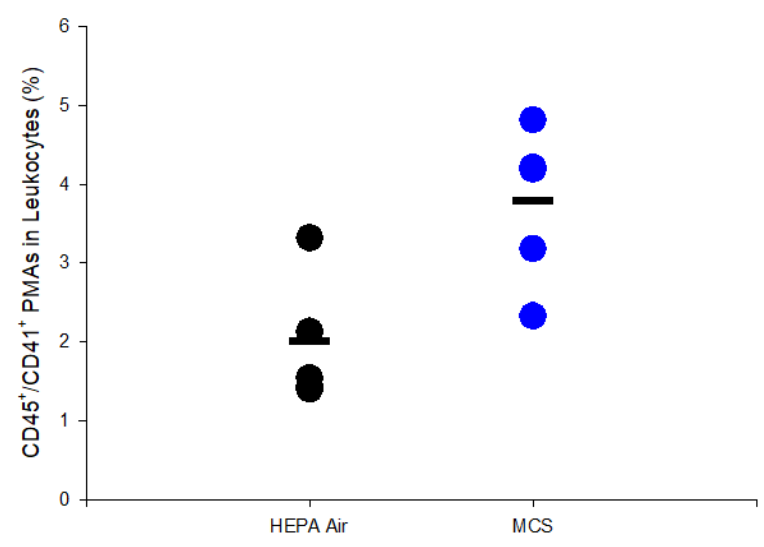

mean \pm se $\quad 2.0 \pm 0.81 \quad 3.7 \pm 1.0$

Figure 8. Effects of acute MCS exposure on PLAs in male mice. Flow cytometry analysis was performed in order to identify CD45 $/ \mathrm{CD} 41^{+} \mathrm{PLAs}$ in $100 \mu \mathrm{L}$ male mouse blood following an acute $4 \mathrm{~d}$ exposure to MCS (50\% of smoke from 12-cigs / 6h; $n=5,5$ ). Representative flow cytometry dot plots of (A.i) control (HEPA-filtered air) versus (A.ii) MCS-exposed mice are displayed. B) Summary data displays each individual mouse exposed to either air or MCS. PLAs are characterized as 20,000 CD45/CD41 double positive events, located in quadrant 2 (Q2). The mice exposed to MCS showed significant increase in PLAs compared with control $\mathrm{p}=0.032$ via Mann-Whitney U test. 


\section{G. Effect of acute e-cig aerosol exposure via inhalation on C57BL/6 male}

mice. As previous mentioned and shown in Conklin et al. 2018, we know that MCS and e-cig aerosols have common aldehyde constituents [32]. Therefore, in our study, we investigated if e-cig exposure induces platelet activation in a similar fashion as our MCS study. We hypothesized that acute exposure to e-cig will lead to platelet activation in vivo as assessed by increased formation of PLAs. C57BL/6 male mice were exposed to e-cig aerosol (blu+; 4d, 6h/d) or HEPAfiltered air (control; 4d, 6h/d). Immediately after the final exposure, the mice were euthanized, and their peripheral blood was collected and prepared for flow cytometric analyses of $\mathrm{CD} 45^{+} / \mathrm{CD} 41^{+}$PLAs. Our results indicate that acute exposure to e-cig aerosol induced no change in PLA formation compared with air control (Figure 9). 
A.i.

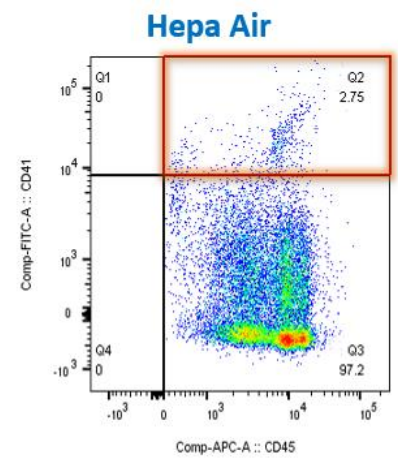

A.ii.

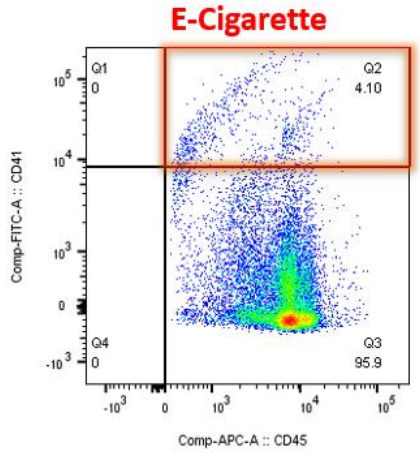

B. C57BL/6 Male Mice: E-Cigarette blu+ $(n=10,10)$

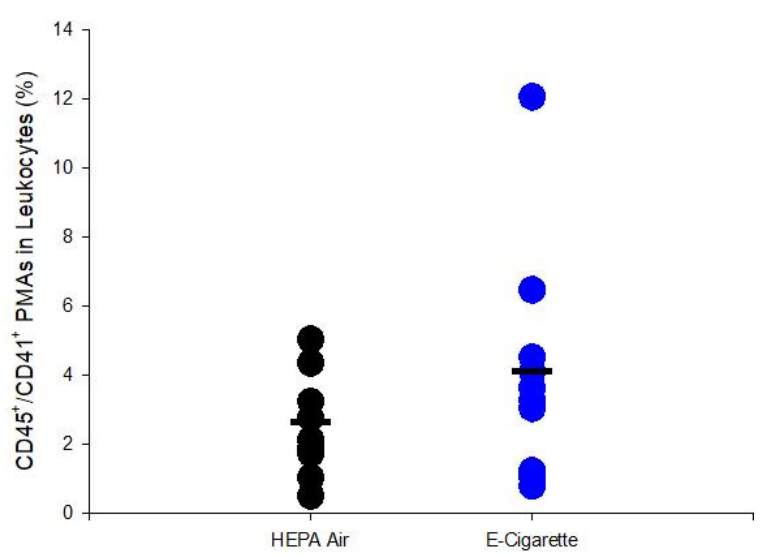

mean \pm se

$4.0 \pm 3.3$

Figure 9. Effects of acute e-cig exposure on PLAs in male mice. Flow cytometry analysis was performed in order to identify $\mathrm{CD} 45^{+} / \mathrm{CD} 41^{+} \mathrm{PLAs}$ in $100 \mu \mathrm{L}$ male mouse blood following an acute $4 \mathrm{~d}$ exposure to e-cig aerosol (blu+ Classic Tobacco; $6 \mathrm{~h} / \mathrm{d} ; \mathrm{n}=10,10)$. Representative flow cytometry dot plots of (A.i) control (HEPA-filtered air) versus (A.ii) e-cig-exposed mice are displayed. B) Summary data displays each individual mouse exposed to either air or e-cig aerosol. PLAs are characterized as 20,000 CD45/CD41 double positive events, located in quadrant 2 (Q2). The mice exposed to e-cig aerosol showed no difference in PLAs compared with control, $p=0.273$ via Mann-Whitney $U$ test. 


\section{H. Effect of acute exposure to formaldehyde via inhalation on C57BL/6}

male mice. In order to assess the effects of formaldehyde on platelet activation, we measured the concentration- and time-dependent exposure impacts on PLAs. We hypothesized that acute (4d or 2-wk) exposure to formaldehyde will induce platelet activation in vivo as assessed by increased formation of PLAs. C57BL/6 male mice were exposed to formaldehyde (2 or $5 \mathrm{ppm}$; $6 \mathrm{~h} / \mathrm{d}, 4 \mathrm{~d}$ or 2 -wk) or HEPA-filtered air (control; 6h/d, 4d or 2-wk). Immediately after final exposure, the mice were euthanized and their peripheral blood was collected and prepared for flow cytometric analyses of $\mathrm{CD} 45^{+} / \mathrm{CD} 41^{+}$PLAs. Our results indicate that male mice acutely exposed to formaldehyde (2 ppm) had no alterations in PLA formation compared with control (Figure 10). As Bhatnagar found that formaldehyde concentrations above 2 ppm increased platelet count [35], we hypothesized that by increasing the concentration, more PLA formation will result. However, treatment with a formaldehyde concentration of $5 \mathrm{ppm}$ still exerted no change (Figure 11). However, the previous report of an increased platelet count resulted from a longer duration (12d) of exposure [35]. Therefore, we completed a two week exposure to a high concentration of formaldehyde, hypothesizing this would change abundance of PLAs. However, we found no changes in PLA formation compared with air controls (Figure 12). 
A.i.

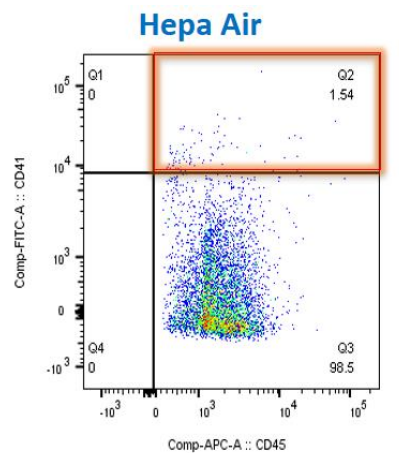

A.ii.

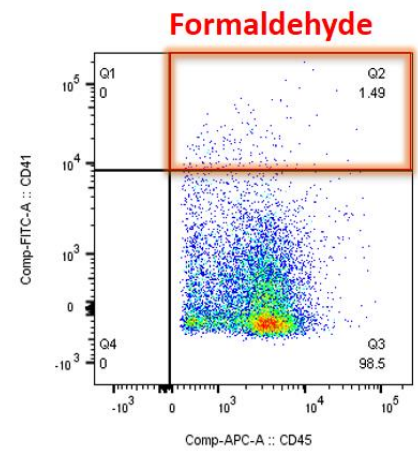

B. C57BL6 Male Mice: 4-d Formaldehyde 2 ppm $(n=10,10)$

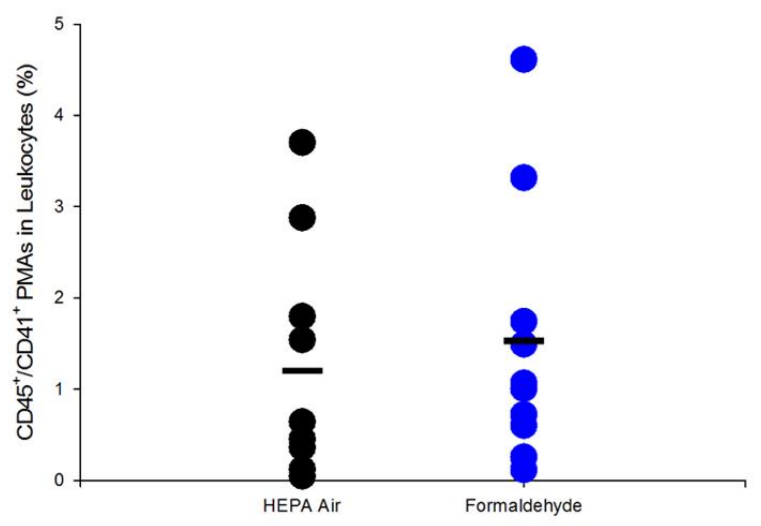

mean \pm se

$1.5 \pm 1.5$

Figure 10. Effects of acute formaldehyde (2 ppm) exposure on PLAs in male mice. Flow cytometry analysis was performed in order to identify CD $45^{+} / \mathrm{CD} 41^{+}$PLAs in $100 \mu \mathrm{L}$ male mouse blood following an acute $4 \mathrm{~d}$ exposure to formaldehyde $(6 \mathrm{~h} / \mathrm{d}$; $n=10,10)$. Representative flow cytometry dot plots of (A.i) control (HEPA-filtered air) versus (A.ii) formaldehyde-exposed mice are displayed. B) Summary data displays each individual mouse exposed to either air or formaldehyde. PLAs are characterized as 20,000 CD45/CD41 double positive events, located in quadrant 2 (Q2). The mice exposed to formaldehyde showed no difference in PLAs compared with control, $\mathrm{p}=0.597$ via Mann-Whitney $U$ test. 
A.i.

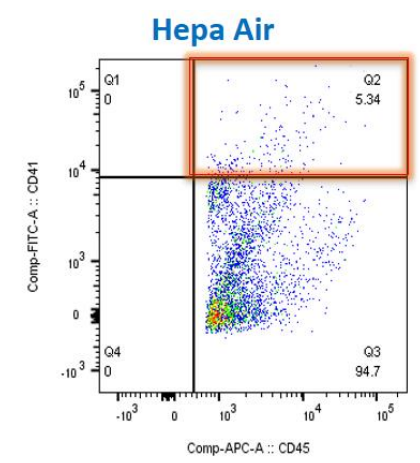

A.ii.

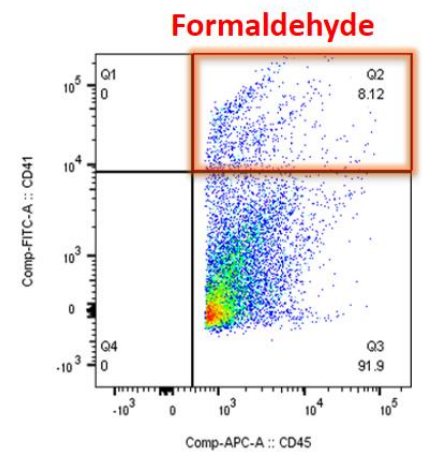

B. C57BL/6 Male Mice: 4-d Formaldehyde $5 \mathrm{ppm}(n=6,8)$

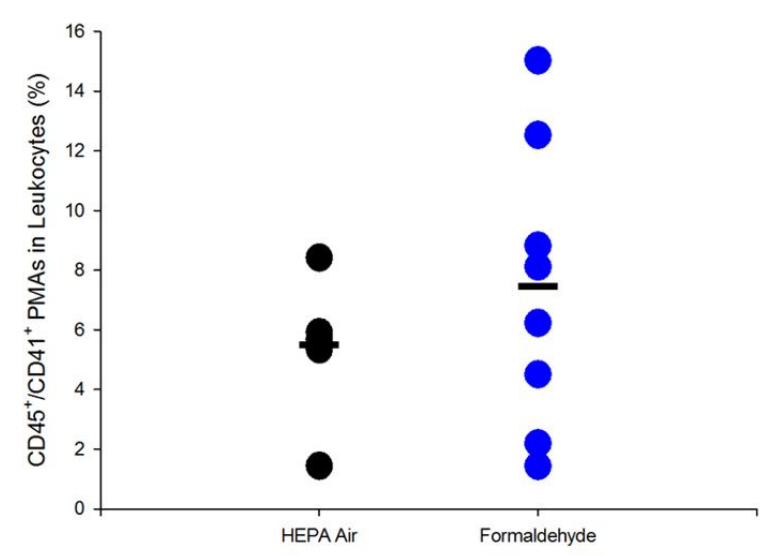

mean \pm se

Figure 11. Effects of acute formaldehyde (5 ppm) exposure on PLAs in male mice. Flow cytometry analysis was performed in order to identify CD45+/CD41+ PLAs in $100 \mu \mathrm{L}$ male mouse blood following an acute $4 \mathrm{~d}$ exposure to formaldehyde $(6 \mathrm{~h} / \mathrm{d}$; $n=6,8)$. Representative flow cytometry dot plots of (A.i) control (HEPA-filtered air) versus (A.ii) formaldehyde-exposed mice are displayed. B) Summary data displays each individual mouse exposed to either air or formaldehyde. PLAs are characterized as 20,000 CD45/CD41 double positive events, located in quadrant 2 (Q2). The mice exposed to formaldehyde showed no difference in PLAs compared with control, $\mathrm{p}=0.368$ via Mann-Whitney $U$ test. 
A.i.

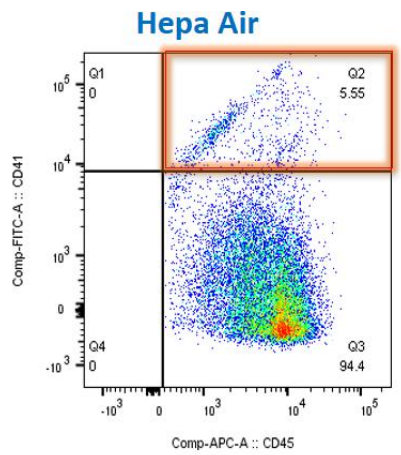

A.ii.

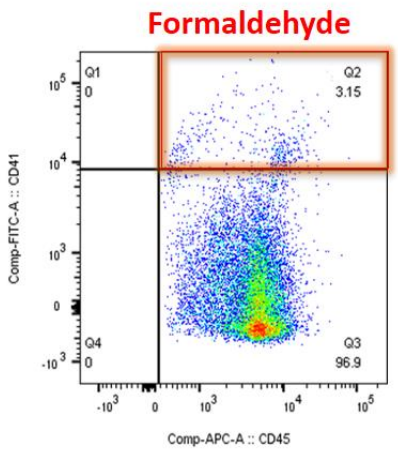

B. C57BL/6 Male Mice: 2-wk Formaldehyde 5 ppm $(n=10,10)$

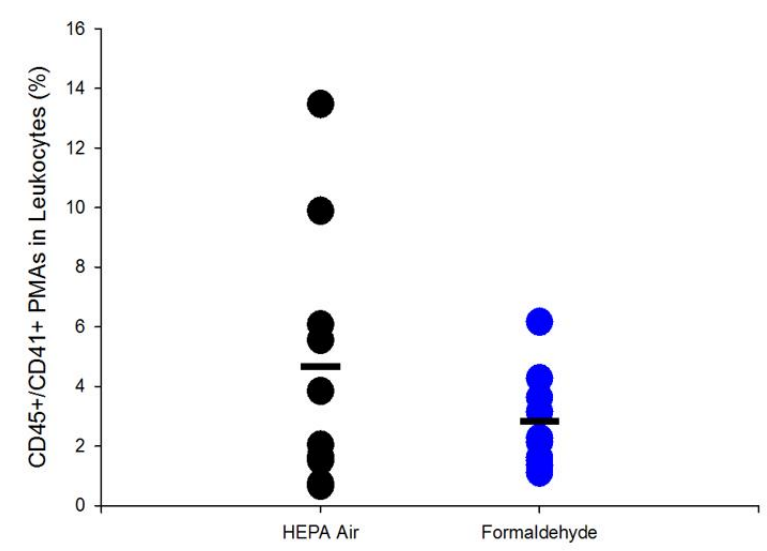

mean \pm se

$2.7 \pm 1.6$

Figure 12. Effects of acute (2-wk) formaldehyde (5 ppm) exposure on PLAs in male mice. Flow cytometry analysis was performed in order to identify $\mathrm{CD}^{2} 5^{+} / \mathrm{CD} 41^{+}$PLAs in $100 \mu \mathrm{L}$ male mouse blood following exposure to formaldehyde $(6 \mathrm{~h} / \mathrm{d} ; \mathrm{n}=10,10)$. Representative flow cytometry dot plots of (A.i) control (HEPA-filtered air) versus (A.ii) formaldehyde-exposed mice are displayed. B) Summary data displays each individual mouse exposed to either air or formaldehyde. PLAs are characterized as 20,000 CD45/CD41 double positive events, located in quadrant 2 (Q2). The mice exposed to formaldehyde showed no difference in PLAs compared with control, $p=0.678$ via Mann-Whitney $U$ test. 


\section{I. Effect of acute exposure to formaldehyde via inhalation on C57BL/6}

female mice. Like our previous studies, we measured the effects of formaldehyde exposure on PLA outcomes in female mice. We hypothesized that acute (4d) exposure to formaldehyde will induce platelet activation in vivo as assessed by increased formation of PLAs. C57BL/6 female mice were exposed to formaldehyde (2 or $5 \mathrm{ppm}$; 6h/d, 4d) or HEPA-filtered air (control; 6h/d, 4d). Immediately after final exposure, the mice were euthanized, and their peripheral blood was collected and prepared for flow cytometric analyses of CD45+/CD41+ PLAs. Our results indicate that female mice acutely exposed to formaldehyde (2 ppm) demonstrated no alterations in PLA formation compared with control (Figure 13). We also increased the concentration of formaldehyde, hypothesizing that by increasing the concentration, more PLA formation will result. However, a formaldehyde concentration of 5 ppm still exerted no change in PLA abundance (Figure 14). Thus, there were no sex-dependent differences in PLA formation in response to formaldehyde exposure. 
A.i.

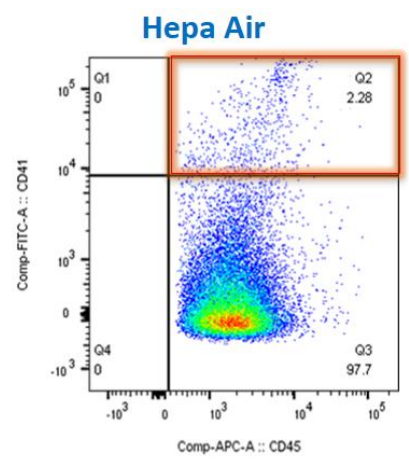

A.ii.

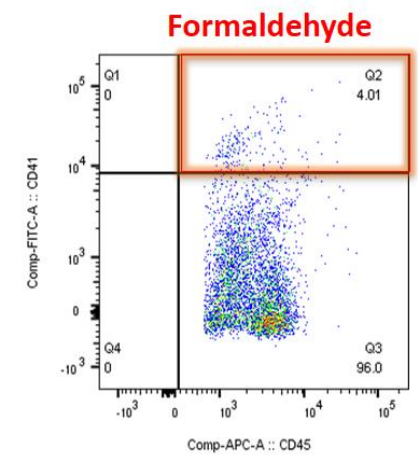

B. C57BL6 Female Mice: 4-d Formaldehyde $2 \mathrm{ppm}(n=8,10)$

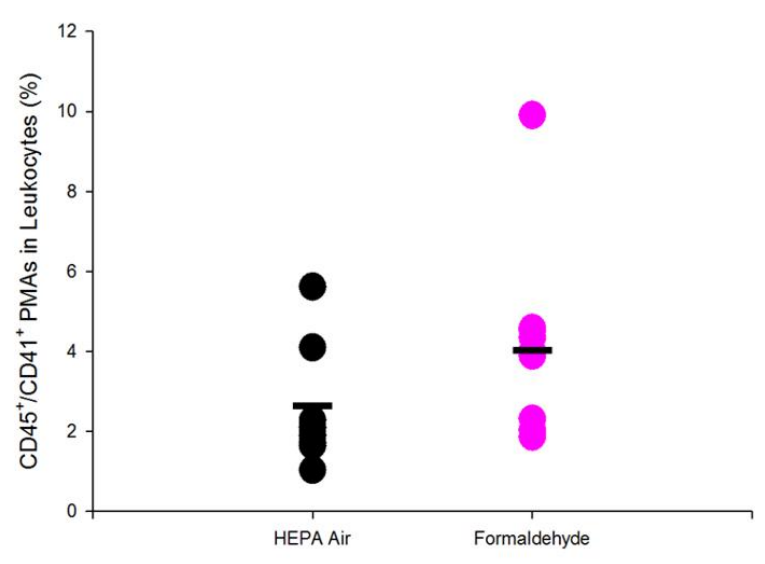

mean \pm se

$3.6 \pm 2.4$

Figure 13. Effects of acute formaldehyde (2 ppm) exposure on PLAs in female mice. Flow cytometry analysis was performed in order to identify CD45+CD41+

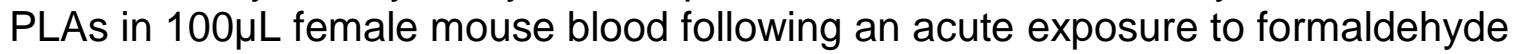
$(6 \mathrm{~h} / \mathrm{d} ; \mathrm{n}=8,10)$. Representative flow cytometry dot plots of (A.i) control (HEPAfiltered air) versus (A.ii) formaldehyde-exposed mice are displayed. B) Summary data displays each individual mouse exposed to either air or formaldehyde. PLAs are characterized as 20,000 CD45/CD41 double positive events, located in quadrant 2 (Q2). The mice exposed to formaldehyde showed no difference in PLAs compared with control, $\mathrm{p}=0.143$ via Mann-Whitney $U$ test. 
A.i.

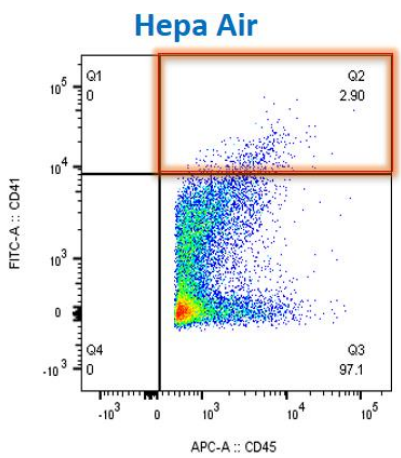

A.ii.

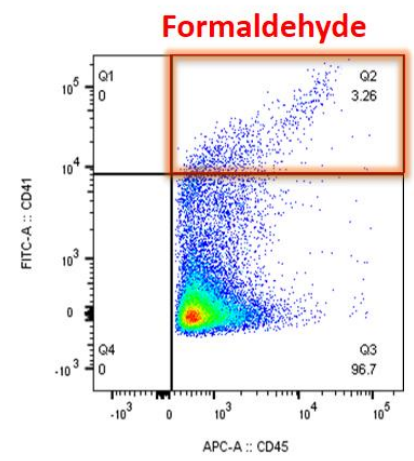

B. C57Bᄂ/6 Female Mice: 4-d Formaldehyde 5 ppm $(n=6,8)$

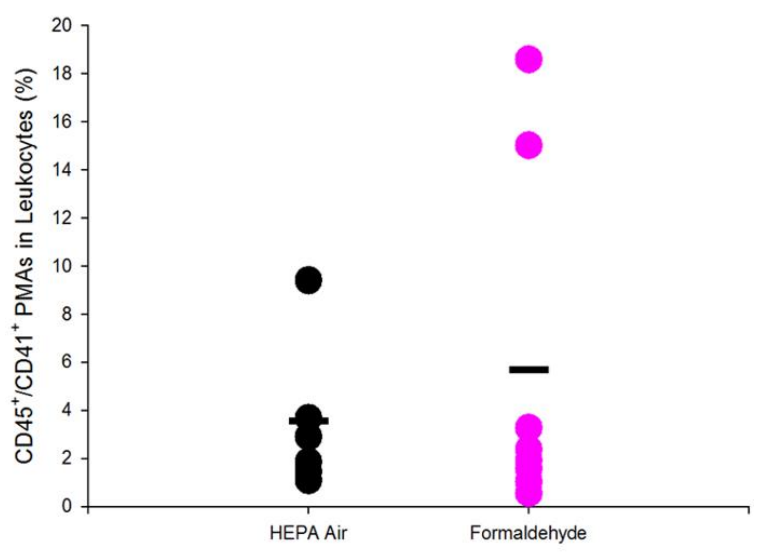

mean \pm se

$5.5 \pm 7.1$

Figure 14. Effects of acute formaldehyde (5 ppm) exposure on PLAs in female mice. Flow cytometry analysis was performed in order to identify CD45 $/$ CD $41^{+}$ PLAs in $100 \mu \mathrm{L}$ female mouse blood following an acute exposure to formaldehyde $(6 \mathrm{~h} / \mathrm{d} ; \mathrm{n}=6,8)$. Representative flow cytometry dot plots of (A.i) control (HEPAfiltered air) versus (A.ii) formaldehyde-exposed mice are displayed. B) Summary data displays each individual mouse exposed to either air or formaldehyde. PLAs are characterized as 20,000 CD45/CD41 double positive events, located in quadrant 2 (Q2). The mice exposed to formaldehyde showed no difference in PLAs compared with control, $\mathrm{p}=0.503$ via Mann-Whitney $U$ test. 


\section{J. Effect of acute exposure to acetaldehyde via inhalation on C57BL/6}

male mice. Acetaldehyde is a metabolite of ethanol. Investigators have demonstrated that both compounds inhibit platelet aggregation [79, 80]. In order to assess the effects of acetaldehyde in PLA formation, we performed a concentration- and time-dependent exposure and analyzed the effects on formation of PLAs via flow cytometry. We hypothesized that acute (4d or 2-wk) exposure to acetaldehyde will inhibit platelet activation in vivo as measured by decreased formation of PLAs. C57BL/6 male mice were exposed to acetaldehyde (5 ppm; 6h/d, 4d or 2-wk) or HEPA-filtered air (control; 6h/d, 4d or 2-wk). Immediately after final exposure, the mice were euthanized, and their peripheral blood was collected and prepared for flow cytometric analyses for identification and quantification of $\mathrm{CD} 45^{+} / \mathrm{CD} 41^{+}$PLAs. Our results indicate that males acutely exposed to $5 \mathrm{ppm}$ acetaldehyde yielded no change in PLA formation compared with air control (Figure 15). By increasing the duration of exposure, we were expecting to exacerbate PLA formation, but our results show no effect in males (Figure 16). 
A.i.

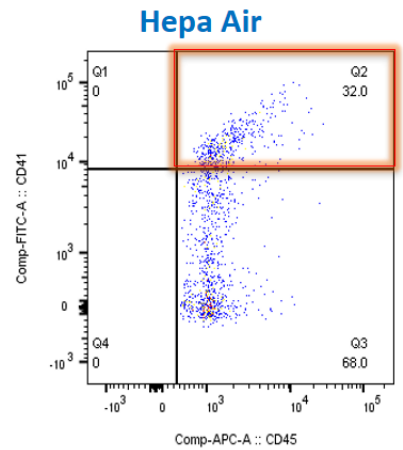

A.ii.

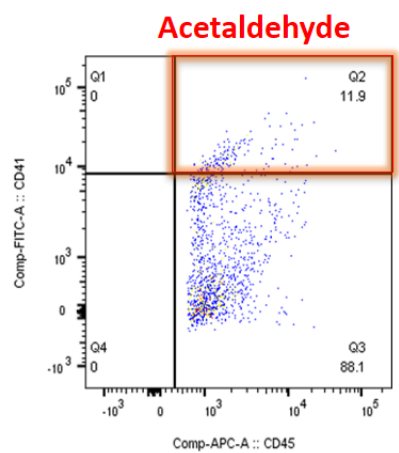

B. C57BL6 Male Mice: 4-d Acetaldehyde 5 ppm $(n=5,5)$

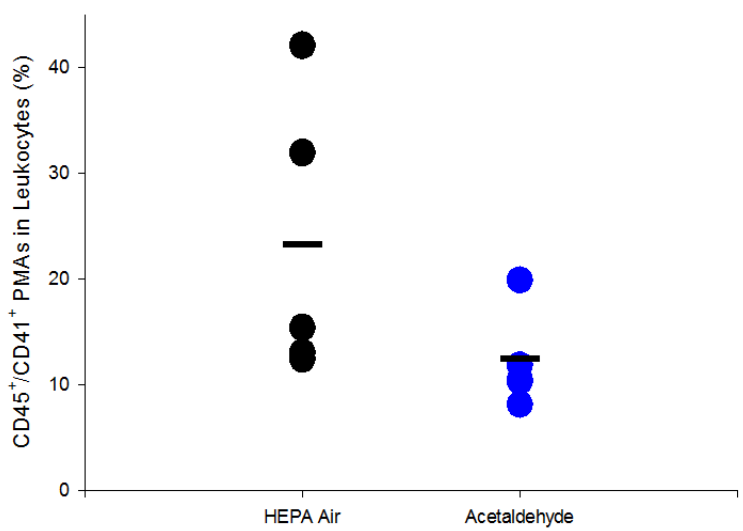

mean \pm se

$12.1 \pm 4.5$

Figure 15. Effects of acute acetaldehyde (5 ppm) exposure on PLAs in male mice. Flow cytometry analysis was performed in order to identify CD45 $/$ CD $41^{+}$PLAs in $100 \mu \mathrm{L}$ male mouse blood following an acute exposure to acetaldehyde $(6 \mathrm{~h} / \mathrm{d}$; $n=5,5)$. Representative flow cytometry dot plots of (A.i) control (HEPA-filtered air) versus (A.ii) acetaldehyde-exposed mice are displayed. B) Summary data displays each individual mouse exposed to either air or acetaldehyde. PLAs are characterized as 20,000 CD45/CD41 double positive events, located in quadrant 2 (Q2). The mice exposed to acetaldehyde showed no difference in PLAs compared with control, $\mathrm{p}=0.056$ via Mann-Whitney $U$ test. 
A.í.

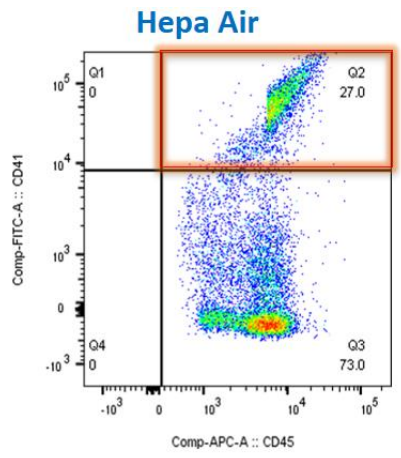

A.ii.

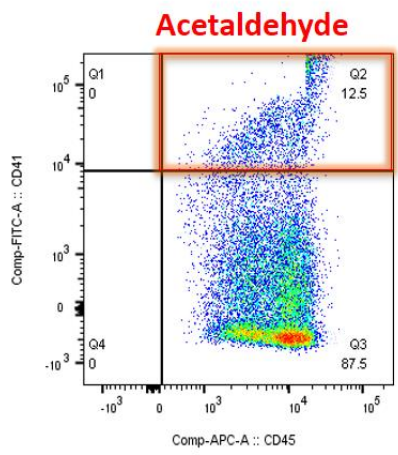

B. C57BL/6 Male Mice: 2-wk Acetaldehyde $5 \mathrm{ppm}(\mathrm{n}=10,10)$

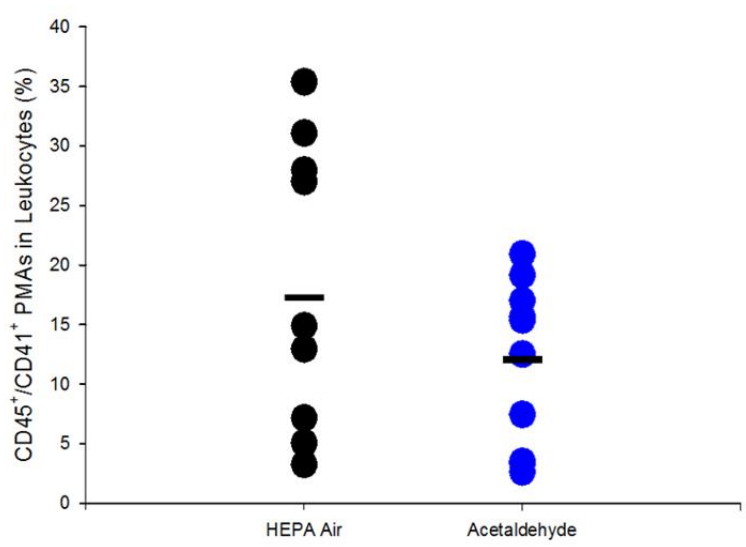

mean \pm se

Figure 16. Effects of acute (2-wk) acetaldehyde (5 ppm) exposure on PLAs in male mice. Flow cytometry analysis was performed in order to identify CD45 $/ C D 41^{+}$ PLAs in $100 \mu \mathrm{L}$ male mouse blood following exposure to acetaldehyde $(6 \mathrm{~h} / \mathrm{d}$; $n=10,10$ ). Representative flow cytometry dot plots of (A.i) control (HEPA-filtered air) versus (A.ii) acetaldehyde-exposed mice are displayed. B) Summary data displays each individual mouse exposed to either air or acetaldehyde. PLAs are characterized as 20,000 CD45/CD41 double positive events, located in quadrant 2 (Q2). The mice exposed to acetaldehyde showed no difference in PLAs compared with control, $p=0.473$ via Mann-Whitney $U$ test. 


\section{K. Effect of acute exposure to acetaldehyde via inhalation on C57BL/6}

female mice. We were interested in determining if the effects of inhaled acetaldehyde exposure are sex dependent. We performed an acute exposure using C57BL/6 female mice and analyzed the effects on formation of PLAs via flow cytometry. These mice were exposed to acetaldehyde (5 ppm; 6h/d, 4d) or HEPA-filtered air (control; 6h/d, 4d). Immediately after final exposure, the mice were euthanized, and their peripheral blood was collected and prepared for flow cytometric analyses for identification and quantification of CD45+CD41+ PLAs. Our results indicate that acute exposure to acetaldehyde yielded no change in PLA formation compared with air control. This effect was not sex-dependent (Figure 17). 
A.i.

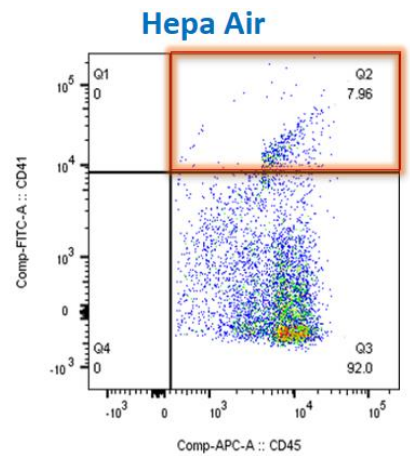

A.ii.

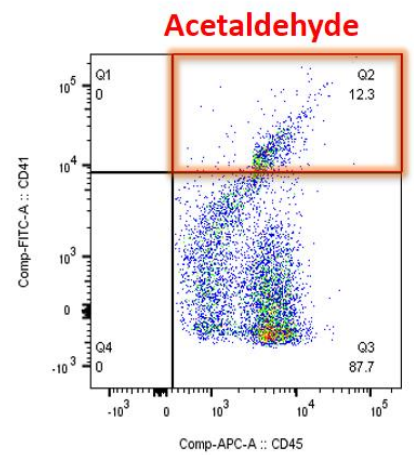

B.

C57BL/6 Female Mice: 4-d Acetaldehyde 5 ppm $(n=5,6)$

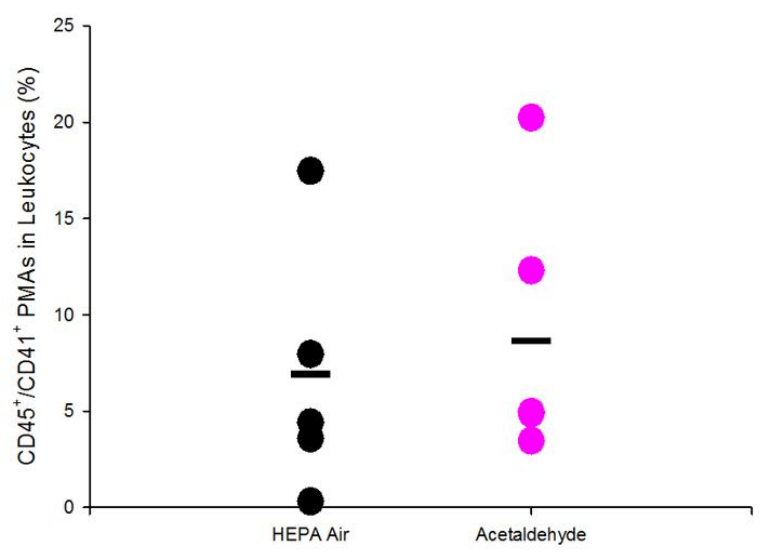

mean \pm se

$6.7 \pm 6.6$

$8.5 \pm 6.6$

Figure 17. Effects of acute acetaldehyde (5 ppm) exposure on PLAs in female mice. Flow cytometry analysis was performed in order to identify CD45 $/ C D 41^{+}$ PLAs in $100 \mu \mathrm{L}$ female mouse blood following exposure to acetaldehyde $(6 \mathrm{~h} / \mathrm{d}$; $n=5,6)$. Representative flow cytometry dot plots of (A.i) control (HEPA-filtered air) versus (A.ii) acetaldehyde-exposed mice are displayed. B) Summary data displays each individual mouse exposed to either air or acetaldehyde. PLAs are characterized as 20,000 CD45/CD41 double positive events, located in quadrant 2 (Q2). The mice exposed to acetaldehyde showed no difference in PLAs compared with control, $\mathrm{p}=0.573$ via Mann-Whitney $U$ test. 


\section{L. Effect of acute and chronic exposure to crotonaldehyde via inhalation}

on C57BL/6 male mice. Crotonaldehyde is an understudied toxicant. Both acrolein and crotonaldehyde are present at high levels in cigarette smoke. Our preliminary results indicate an increase in PLA formation in male mice acutely exposed to MCS. Acrolein also exerts the same effect. Given that acrolein and crotonaldehyde are similar compounds, we hypothesized that acute (4d) or chronic (12-wk) exposure to crotonaldehyde will induce platelet activation in vivo as assessed by increased formation of PLAs. C57BL/6 male mice were exposed to crotonaldehyde (1 ppm; 6h/d, 4d or 12-wk) or HEPA-filtered air (control; 4d or 12-wk, 6h/d). Immediately after final exposure, the mice were euthanized and their peripheral blood was collected and prepared for flow cytometric analyses of CD45 $/$ CD41 + PLAs. These data suggest that acute exposure to crotonaldehyde significantly decreases PLA formation compared with air control. Chronic exposure to crotonaldehyde yielded no change in PLA formation compared with air control (Figure 18). 

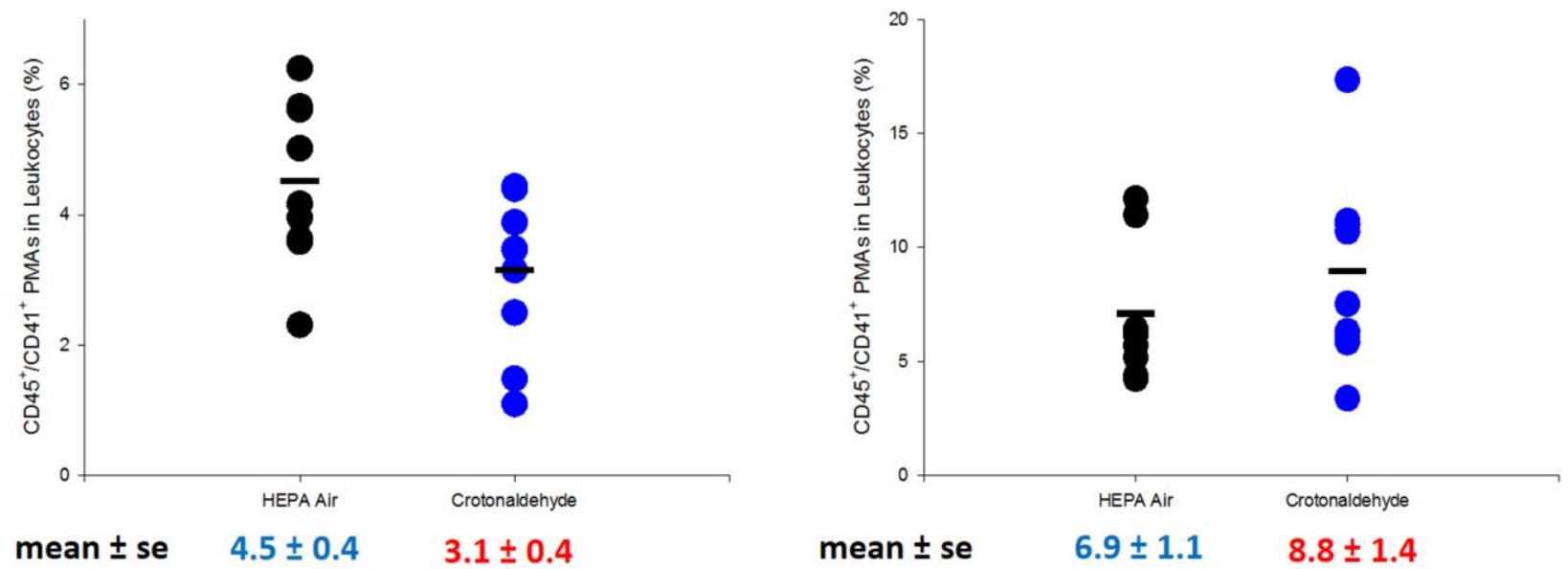

Figure 18. Effects of $(A)$ acute $4 \mathrm{~d}$ or $(B)$ chronic 12-wk crotonaldehyde exposure in male mice. Flow cytometry analyses were performed in order to identify $\mathrm{CD} 45^{+} / \mathrm{CD} 41^{+}$PLAs in $100 \mu \mathrm{L}$ male mouse blood following exposure to crotonaldehyde ( $1 \mathrm{ppm} ; 6 \mathrm{~h} / \mathrm{d} ; \mathrm{n}=9,9$ and $n=8,9$, respectively in each study). PLAs are characterized as 20,000 CD45/CD41 double positive events, located in quadrant 2 (Q2). There is a significant decrease in PLA formation following acute exposure to crotonaldehyde compared with control (HEPA-filtered air), $p=0.042$ via Mann-Whitney $U$ test. No changes in PLA formation resulted from chronic exposure compared with control via Mann-Whitney U test. 


\section{CHAPTER 4:}

\section{DISCUSSION}

Here, we explored the influences of concentration-dependent acrolein and e-cig flavoring additives (eugenol, cinnamaldehyde, vanillin, and menthol) on phasespecific ADP-induced platelet aggregation. When platelets activate, they undergo biphasic activity. Primary aggregation, or phase 1 , is a direct effect of the stimulant/agonist. The stimulant induces a shape change, with subsequent granule secretion. Secondary aggregation, or phase 2, occurs as a result of platelet-platelet interactions due to the action of granule contents recruiting and activating surrounding platelets. To our knowledge, no study has investigated the direct effects of these compounds on phase 1 and phase 2 platelet aggregation as a potential mechanism of total aggregation. By identifying what phase is more affected, we will more fully understand the mechanism of these pro-thrombotic agents.

Selley et al. investigated the effects of acrolein on ADP-induced aggregation and found that acrolein exerted no effect on total aggregation compared with control (ADP-alone) [75]. Our results in Figure 3 were able to duplicate the published data, demonstrating that concentration-dependent effects of acrolein on total aggregation did not differ compared with our control. However, we observed a significant decrease in phase 1 activity at 10 and $30 \mu \mathrm{M}$ 
and an increase in phase 2 at those same concentrations. We hypothesize that at those levels, direct exposure causes rapid exocytosis of platelet granules, a direct reflection of phase 1 activity. Thus, aggregation in phase 2 occurred much faster, exhibited as an increase in response. Higher concentrations exerted no effect on biphasic activity. This could be because the platelets became fixed prior to ADP-induction.

Eugenol is a clove-oil derived flavoring compound [81]. This chemical is also a potent anti-inflammatory agent [82-85], suggesting anti-platelet behavior. In our results, we observed a decreased response of total and phase 2 aggregation with exposure to eugenol at increasing concentrations (Figure 4). Upon close observation, it appears that we only see one phase of aggregation, the primary phase. These results suggest that phase 2 is suppressed or inhibited. In fact, at the highest concentration tested $(100 \mu \mathrm{M})$, we observed disaggregation in which our traces reversed post-phase 1 activity. Together, we believe eugenol is an inhibitor of platelet aggregation.

Cinnamaldehyde is a cinnamon-derived flavoring compound. It is an ingredient in the essential oils of cinnamon leaves and bark, and it has been used as an additive in many aerosol fragrances as well as some household products. Cinnamaldehyde is also a known peripheral vasodilator [86, 87]. When the blood vessel is dilated, platelets tend to be inactive. This suggests that cinnamaldehyde functions as an inhibitor of platelet aggregation. Some studies have in fact proven the inhibitory effect of cinnamaldehyde $[88,89]$. We suspected to observe similar results as seen with eugenol. However, our result 
did not agree. We observed no change in total, phase 1 , and phase 2 aggregation with exposure to cinnamaldehyde compared with control (Figure 5). However, Takenaga et al. 1987 completed their study using collagen and thrombin as their aggregating agents [89], whereas our study only used ADP. This suggests that cinnamaldehydes effect on platelet aggregation is agonistdependent.

Vanillin, a vanilla-derived flavoring compound in e-cigs, exerts anti-platelet aggregation effects in vitro via arachidonic acid-induction [90, 91]. Our preliminary results indicate vanillin has no effect on ADP-induced aggregation as well as no phase 1 or phase 2 responses (Figure 6). We hypothesize that vanillin action is dependent upon arachidonic acid-receptor activation and not responsive to ADP-receptor activation.

Menthol is mint-derived flavoring compound. Menthol triggers a cooling sensation byway of dermal, oral, or inhalation exposures [92]. As indicated in the literature, menthol inhibits collagen- and ADP-induced platelet aggregation in vitro [93]. However, like our cinnamaldehyde responses, our results did not compare with the literature. Additionally, phase 1 and phase 2 were unaffected compared with control (Figure 7). Since total aggregation did not show inhibitory responses, we believe our data is inconclusive and needs to be refined.

Though much of the data appear inconclusive, we do believe our data are indicative of agonist-dependent effects. This suggests that certain e-cig-derived flavoring compounds or aldehydes may act through different platelet receptors 
(e.g. ADP, collagen, thrombin, arachidonic acid, or epinephrine). This hypothesis will be tested in future studies.

Also in this study, we investigated the level- and duration-dependent effects of exposure to mainstream cigarette smoke (MCS), e-cig aerosol, and aldehydes on PLA formation in vivo. Under the conditions tested, acute exposure to MCS caused a significant increase in PLA formation in C57BL/6 male mice. Nocella et al. 2018 and Carnevale et al. 2016 compared the impact of e-cigs with conventional cigarettes in smokers and nonsmokers, specifically with endpoints of oxidative stress, vascular function, and platelet function [94, 95]. These studies revealed that exposure to conventional cigarettes induced changes in platelet activation markers (sCD40L and SP-selectin) as well as increased collageninduced platelet aggregation [94]. However, exposure to e-cig did not exert the same effects in these markers. Our lab has published that e-cig aerosols generate unsaturated aldehyde at much lower levels than saturated aldehydes [32], whereas MCS encompasses high concentrations of all four aldehydes. Since we did not observe a change in PLA formation due to e-cig aerosol exposure, we hypothesize that the unsaturated aldehydes may be the culprits or agonists of PLA formation, not the saturated aldehydes.

To our knowledge, no study has explored the relationship between saturated aldehyde exposure and PLA formation as measured by flow cytometry. Under the conditions tested in our studies, exposure to formaldehyde (1 ppm or 5 ppm), at any duration, exerted no effect on PLA formation in both males and females compared with control. Similarly, exposure to acetaldehyde exerted no 
significant changes. Acetaldehyde exerts inhibitory responses to platelet aggregation in humans and rodents [79, 80]. In Figure 13, our Rank Sum Test revealed acetaldehyde-induced a decrease in PLA formation compared with airexposed control with a p-value of 0.056 . Though insignificant, we believe the effect may be real if given a greater $n$.

As previously mentioned, Sithu et al. found that acute $(1 \mathrm{~d}, 6 \mathrm{~h})$ and subchronic (4d, 6h/d as indicated in the literature) exposure to acrolein (1 ppm) increased PLA formation compared with air control [38]. We believed that exposure to crotonaldehyde (1 ppm) would exert similar effects given the similarities in chemical structure and reactivity. Under the conditions tested in our study, acute exposure to crotonaldehyde resulted in an inhibitory response of PLA formation compared with control (Figure 18A). A potential hypothesis is that exposure to crotonaldehyde induces NO production. This action causes inhibitory effects of platelet activation, which may help to explain the inhibitory response of PLA formation in our study. More studies are needed to confirm this hypothesis. Chronic exposure had no effect on PLA formation as compared with control. We would also need to increase our $n$ to validate these data.

\section{CONCLUSION}

Based on our studies, we conclude that exposure to some HPHCs such as aldehyde and flavorings in tobacco-derived aerosols may play a significant role in platelet activation. More research is required to explore the pathophysiological mechanisms of platelet activation and how our HPHCs influence those mechanisms. 


\section{CHAPTER 5:}

\section{FUTURE DIRECTIONS}

Given all tobacco products on the market, new possible health concerns have been exposed. Aside from what is known about their respiratory effects, our lab aims to uncover the adverse cardiovascular effects induced by exposure to these products and their constituents. Future in vitro and in vivo studies will explore the effects of these aldehydes with or without nicotine. Nicotine is a highly addictive substance that accelerates heart rate as well as increases blood pressure [23, 96-98]. Nicotine has been shown to inhibit platelet aggregation in human platelets [99]. In combination with aldehydes, we will test if nicotine offers a synergistic, inhibitory, or additive effect on platelet aggregation, PLA formation, as well as other platelet activation markers.

We are furthermore proposing that the actions of the tobacco-derived constituents on platelet activation are mediated via transient receptor potential ankyrin-1 (TRPA1). For other future directions, we will test if the TRPA1 receptor mediates platelet activation in each of our studies that displayed positive outcomes. Investigators have postulated that effects observed due to exposure to acrolein and/or other aldehydes are mediated via TRPA1-dependent activation in the lungs and in the vasculature $[72,100,101]$. To our knowledge, there is no data to demonstrate mechanistically that the effects of exposure to acrolein on 
platelet activation are mediated via TRPA1. TRPA1 is an irritant/pain responder linked to pain and inflammation and is activated by environmental toxicants such as cigarette smoke. Furthermore, TRPA1 protects against endogenous and exogenous acrolein-induced cardiopulmonary toxicity in vivo at high concentrations. Additionally, female wild-type mice were proven to be protected from acrolein-induced mortality when compared with male wild-types [72]. We hypothesize that the effects seen with acrolein-induced cardiopulmary toxicity are both TRPA1- and sex-dependent. Previous studies have shown formaldehydeinduced lung inflammation is mediated via progesterone and estradiol, which is a female hormone-specific effect [102-104]. Another study found that the TRPA1 channel may the target of sex-dependent issue related to migraine pain, suggesting that women express more pain-related sensations compared to men [105]. This may add to our hypothesis of sex-dependent effects of TRPA1mediated platelet activation. Our future directions are to test the relationship between cigarette smoke exposure, TRPA1 and thrombosis. We will also investigate sex-specific differences that are potentially TRPA1-dependent as well.

The purpose of this research was to examine the effects of exposure to MCS, e-cigs, flavorings, as well as the HPHCs on platelet activation as a marker of thrombosis. Altogether, the results presented indicate that cigarette smoke can exacerbate platelet pathophysiological outcomes. Our goal in the future is to discover the potential mechanism in which tobacco-derived aerosols induce platelet activation. Ultimately, there is a huge gap of knowledge concerning the 
effects of smoking and vaping on cardiovascular health, and we intend to bridge together that understanding and combat CVD. 


\section{REFERENCES}

1. (NIH), N.I.o.H. Ischemic Heart Disease. Available from:

https://www.nhlbi.nih.gov/health-topics/ischemic-heart-disease.

2. (NIH), N.I.o.H. Cardiovascular Disease. 2017; Available from:

https://nccih.nih.gov/health/heart-disease.

3. (CDC), C.f.D.C.a.P., Coronary Artery Disease.

4. (AHA), A.H.A., Heart Disease and Stroke Statistics 2017 At-a-Glance. 2017.

5. National Center for Chronic Disease, P., S. Health Promotion Office on, and Health, Reports of the Surgeon General, in The Health Consequences of Smoking-50 Years of Progress: A Report of the Surgeon General. 2014, Centers for Disease Control and Prevention (US): Atlanta (GA).

6. Olasky, S.J., D. Levy, and A. Moran, Second hand smoke and cardiovascular disease in Low and Middle Income Countries: a case for action. Global heart, 2012. 7(2): p. 151160.e5.

7. Barnoya, J. and A. Navas-Acien, Protecting the world from secondhand tobacco smoke exposure: where do we stand and where do we go from here? Nicotine \& tobacco research : official journal of the Society for Research on Nicotine and Tobacco, 2013. 15(4): p. 789-804.

8. Yankelevitz, D.F., et al., Second-Hand Tobacco Smoke in Never Smokers Is a Significant Risk Factor for Coronary Artery Calcification. JACC: Cardiovascular Imaging, 2013. 6(6): p. 651-657.

9. (AHA), A.H.A., FACTS: What are you smoking? Smoking and Cardiovascular Disease (CVD).

10. Bhatnagar, A., Environmental cardiology: studying mechanistic links between pollution and heart disease. Circ Res, 2006. 99(7): p. 692-705.

11. (CDC), C.f.D.C.a.P., Smoking and Cardiovascular Disease.

12. Al-Qazzaz, N.K., et al., Cognitive impairment and memory dysfunction after a stroke diagnosis: a post-stroke memory assessment. Neuropsychiatric disease and treatment, 2014. 10: p. 1677-1691.

13. Ambuj Roy, I.R., Samer Jabbour, Dorairaj Prabhakaran, Tobacco and Cardiovascular Disease: A Summary of Evidence. Cardiovascular, Respiratory, and Related Disorders, 2017.

14. Hackshaw, A., et al., Low cigarette consumption and risk of coronary heart disease and stroke: meta-analysis of 141 cohort studies in 55 study reports. BMJ (Clinical research ed.), 2018. 360: p. j5855-j5855.

15. Banks, E., et al., Tobacco smoking and risk of 36 cardiovascular disease subtypes: fatal and non-fatal outcomes in a large prospective Australian study. BMC Medicine, 2019. 17(1): p. 128. 
16. Aune, D., et al., Tobacco smoking and the risk of sudden cardiac death: a systematic review and meta-analysis of prospective studies. European journal of epidemiology, 2018. 33(6): p. 509-521.

17. Morris, P.B., et al., Cardiovascular Effects of Exposure to Cigarette Smoke and Electronic Cigarettes: Clinical Perspectives From the Prevention of Cardiovascular Disease Section Leadership Council and Early Career Councils of the American College of Cardiology. J Am Coll Cardiol, 2015. 66(12): p. 1378-91.

18. Morris, P.B., et al., Cardiovascular Effects of Exposure to Cigarette Smoke and Electronic Cigarettes. Clinical Perspectives From the Prevention of Cardiovascular Disease Section Leadership Council and Early Career Councils of the American College of Cardiology, 2015. 66(12): p. 1378-1391.

19. Fairchild, A.L., R. Bayer, and J. Colgrove, The renormalization of smoking? E-cigarettes and the tobacco "endgame". N Engl J Med, 2014. 370(4): p. 293-5.

20. Berg, C.J., et al., Attitudes toward E-Cigarettes, Reasons for Initiating E-Cigarette Use, and Changes in Smoking Behavior after Initiation: A Pilot Longitudinal Study of Regular Cigarette Smokers. Open journal of preventive medicine, 2014. 4(10): p. 789-800.

21. Bhatnagar, A., Are Electronic Cigarette Users at Increased Risk for Cardiovascular Disease? JAMA Cardiology, 2017. 2(3): p. 237-238.

22. Farsalinos, K.E. and R. Polosa, Safety evaluation and risk assessment of electronic cigarettes as tobacco cigarette substitutes: a systematic review. Therapeutic advances in drug safety, 2014. 5(2): p. 67-86.

23. Benowitz, N.L. and A.D. Burbank, Cardiovascular toxicity of nicotine: Implications for electronic cigarette use. Trends in cardiovascular medicine, 2016. 26(6): p. 515-523.

24. Tayyarah, R. and G.A. Long, Comparison of select analytes in aerosol from e-cigarettes with smoke from conventional cigarettes and with ambient air. Regulatory Toxicology and Pharmacology, 2014. 70(3): p. 704-710.

25. Chen, J., C. Bullen, and K. Dirks, A Comparative Health Risk Assessment of Electronic Cigarettes and Conventional Cigarettes. Int J Environ Res Public Health, 2017. 14(4).

26. McNeill A BL, C.R., Hitchman SC, Hajek P, McRobbie H, E-cigarettes: an evidence update. Public Health England, 2015: p. 1-113.

27. Sassano, M.F., et al., Evaluation of e-liquid toxicity using an open-source highthroughput screening assay. PLoS biology, 2018. 16(3): p. e2003904-e2003904.

28. Mishra, A., et al., Harmful effects of nicotine. Indian journal of medical and paediatric oncology : official journal of Indian Society of Medical \& Paediatric Oncology, 2015. 36(1): p. 24-31.

29. Onor, I.O., et al., Clinical Effects of Cigarette Smoking: Epidemiologic Impact and Review of Pharmacotherapy Options. International journal of environmental research and public health, 2017. 14(10): p. 1147.

30. Goniewicz, M.L., et al., Comparison of Nicotine and Toxicant Exposure in Users of Electronic Cigarettes and Combustible Cigarettes. JAMA Network Open, 2018. 1(8): p. e185937-e185937.

31. Ogunwale, M.A., et al., Aldehyde Detection in Electronic Cigarette Aerosols. ACS Omega, 2017. 2(3): p. 1207-1214.

32. Conklin, D.J., et al., Electronic cigarette-generated aldehydes: The contribution of e-liquid components to their formation and the use of urinary aldehyde metabolites as biomarkers of exposure. Aerosol Science and Technology, 2018. 52(11): p. 1219-1232.

33. Benowitz, N.L. and J.B. Fraiman, Cardiovascular effects of electronic cigarettes. Nat Rev Cardiol, 2017. 14(8): p. 447-456. 
34. Khlystov, A. and V. Samburova, Flavoring Compounds Dominate Toxic Aldehyde Production during E-Cigarette Vaping. Environmental Science \& Technology, 2016. 50(23): p. 13080-13085.

35. Bhatnagar, A., E-Cigarettes and Cardiovascular Disease Risk: Evaluation of Evidence, Policy Implications, and Recommendations. Current Cardiovascular Risk Reports, 2016. 10(7): p. 24.

36. Luo, J., et al., Mechanisms of acrolein-induced myocardial dysfunction: implications for environmental and endogenous aldehyde exposure. Am J Physiol Heart Circ Physiol, 2007. 293(6): p. H3673-84.

37. DeJarnett, N., et al., Acrolein exposure is associated with increased cardiovascular disease risk. J Am Heart Assoc, 2014. 3(4).

38. Sithu, S.D., et al., Exposure to acrolein by inhalation causes platelet activation. Toxicol Appl Pharmacol, 2010. 248(2): p. 100-10.

39. (NTP), N.T.P., Report on Carcinogens: Formaldehyde. 14.

40. Egle, J.L., Jr. and P.M. Hudgins, Dose-dependent sympathomimetic and cardioinhibitory effects of acrolein and formaldehyde in the anesthetized rat. Toxicol Appl Pharmacol, 1974. 28(3): p. 358-66.

41. (NTP), N.T.P., Report on Carcinogens: Acetaldehyde. 1991(14).

42. Egle, J.L., Jr., Effects of inhaled acetaldehyde and propionaldehyde on blood pressure and heart rate. Toxicol Appl Pharmacol, 1972. 23(1): p. 131-5.

43. Pawlak, D., B. Malinowska, and W. Buczko, Cardiovascular effects of acetaldehyde in pithed rats. Pharmacology, 1992. 45(2): p. 83-9.

44. Egle, J.L., Jr., P.M. Hudgins, and F.M. Lai, Cardiovascular effects of intravenous acetaldehyde and propionaldehyde in the anesthetized rat. Toxicol Appl Pharmacol, 1973. 24(4): p. 636-44.

45. Kupari, M., et al., Cardiovascular Effects of Acetaldehyde Accumulation after Ethanol Ingestion: Their Modification by B-Adrenergic Blockade and Alcohol Dehydrogenase Inhibition. Alcoholism: Clinical and Experimental Research, 1983. 7(3): p. 283-288.

46. (ATSDR), A.f.T.S.a.D.R., Toxicological Profile for Acrolein.

47. Agency, U.E.P., Acrolein. 2016.

48. Weber-Tschopp, A., et al., [Experimentally induced irritating effects of acrolein on men (author's transl)]. Int Arch Occup Environ Health, 1977. 40(2): p. 117-30.

49. ATSDR, Toxic Substances Portal - Crotonaldehyde. 2014.

50. OSHA, Crotonaldehyde. 1990.

51. Fetterman, J.L., et al., Flavorings in Tobacco Products Induce Endothelial Cell Dysfunction. Arterioscler Thromb Vasc Biol, 2018. 38(7): p. 1607-1615.

52. Wang, G.R., et al., Mechanism of platelet inhibition by nitric oxide: in vivo phosphorylation of thromboxane receptor by cyclic GMP-dependent protein kinase. Proceedings of the National Academy of Sciences of the United States of America, 1998. 95(9): p. 4888-4893.

53. Riddell, D.R. and J.S. Owen, Nitric oxide and platelet aggregation. Vitam Horm, 1999. 57: p. 25-48.

54. Nong, Z., et al., Nitric Oxide Inhalation Inhibits Platelet Aggregation and PlateletMediated Pulmonary Thrombosis in Rats. Circulation Research, 1997. 81(5): p. 865-869.

55. Samama, C.M.M.D.P., et al., Inhibition of Platelet Aggregation by Inhaled Nitric Oxide in Patients with Acute Respiratory Distress Syndrome. Anesthesiology: The Journal of the American Society of Anesthesiologists, 1995. 83(1): p. 56-65. 
56. Gkaliagkousi, E., et al., Decreased platelet nitric oxide contributes to increased circulating monocyte-platelet aggregates in hypertension. Eur Heart J, 2009. 30(24): p. 3048-54.

57. Ho-Tin-Noe, B., Y. Boulaftali, and E. Camerer, Platelets and vascular integrity: how platelets prevent bleeding in inflammation. Blood, 2018. 131(3): p. 277-288.

58. Finsterbusch, M., et al., Measuring and interpreting platelet-leukocyte aggregates. Platelets, 2018. 29(7): p. 677-685.

59. Thomas, D.P., Effect of Catecholamines on Platelet Aggregation caused by Thrombin. Nature, 1967. 215(5098): p. 298-299.

60. Anfossi, G. and M. Trovati, Role of catecholamines in platelet function: pathophysiological and clinical significance. Eur J Clin Invest, 1996. 26(5): p. 353-70.

61. Inoue, T., Cigarette Smoking as a Risk Factor of Coronary Artery Disease and its Effects on Platelet Function. Tobacco Induced Diseases, 2004. 2(1): p. 2-2.

62. P, R.R.a.T., Chapter 3Platelet Adhesion to Vascular Walls. 2010.

63. Bhattacharyya, K.G.a.M., Overview of Platelet Physiology: Its Hemostatic and Nonhemostatic Role in Disease Pathogenesis. 2014.

64. Cerletti, C., et al., Platelet-leukocyte interactions in thrombosis. Thromb Res, 2012. 129(3): p. 263-6.

65. Goniewicz, M.L., et al., Levels of selected carcinogens and toxicants in vapour from electronic cigarettes. Tobacco Control, 2014. 23(2): p. 133.

66. Shields, P.G., et al., A Review of Pulmonary Toxicity of Electronic Cigarettes in the Context of Smoking: A Focus on Inflammation. Cancer epidemiology, biomarkers \& prevention : a publication of the American Association for Cancer Research, cosponsored by the American Society of Preventive Oncology, 2017. 26(8): p. 11751191.

67. Chun, L.F., et al., Pulmonary toxicity of e-cigarettes. Am J Physiol Lung Cell Mol Physiol, 2017. 313(2): p. L193-I206.

68. Shahab, L., et al., Nicotine, Carcinogen, and Toxin Exposure in Long-Term E-Cigarette and Nicotine Replacement Therapy Users: A Cross-sectional Study. Ann Intern Med, 2017. 166(6): p. 390-400.

69. Paniccia, R., et al., Platelet function tests: a comparative review. Vascular health and risk management, 2015. 11: p. 133-148.

70. Conklin, D.J., et al., Biomarkers of Chronic Acrolein Inhalation Exposure in Mice: Implications for Tobacco Product-Induced Toxicity. Toxicological Sciences, 2017. 158(2): p. 263-274.

71. O'Toole, T.E., et al., Acrolein decreases endothelial cell migration and insulin sensitivity through induction of let-7a. Toxicological sciences : an official journal of the Society of Toxicology, 2014. 140(2): p. 271-282.

72. Conklin, D.J., et al., Role of TRPA1 in acute cardiopulmonary toxicity of inhaled acrolein. Toxicol Appl Pharmacol, 2017. 324: p. 61-72.

73. Michelson, A.D. and P.E. Newburger, Platelets and leukocytes: aggregate knowledge. Blood, 2007. 110(3): p. 794.

74. Sithu, S.D., et al., Platelet Sensitivity is Increased by Acrolein. The FASEB Journal, 2008. 22(1_supplement): p. 897.6-897.6.

75. Selley, M.L., et al., Effects of acrolein on human platelet aggregation. Chem Biol Interact, 1990. 76(1): p. 101-9.

76. Muthumalage, T., et al., Inflammatory and Oxidative Responses Induced by Exposure to Commonly Used e-Cigarette Flavoring Chemicals and Flavored e-Liquids without Nicotine. Front Physiol, 2017. 8: p. 1130. 
77. Ciftci, O., et al., Mentholated cigarette smoking and brachial artery, carotid artery, and aortic vascular function. Turk Kardiyol Dern Ars, 2009. 37(4): p. 234-40.

78. Salahuddin, S., D. Prabhakaran, and A. Roy, Pathophysiological Mechanisms of TobaccoRelated CVD. Global Heart, 2012. 7(2): p. 113-120.

79. Spertini, O., J. Hauert, and F. Bachmann, Reaction of acetaldehyde with human platelets. Thromb Haemost, 1992. 67(1): p. 126-30.

80. Zoucas, E. and S. Bengmark, Effect of acetaldehyde on rat platelet aggregation in vivo and in vitro. Res Exp Med (Berl), 1987. 187(1): p. 43-8.

81. USTPO, Eugenol enhancement of transdermal drug delivery. US Patent 4888362. 1989.

82. Barboza, J.N., et al., An Overview on the Anti-inflammatory Potential and Antioxidant Profile of Eugenol. Oxidative medicine and cellular longevity, 2018. 2018: p. 39572623957262.

83. Ma, N., et al., Evaluation on antithrombotic effect of aspirin eugenol ester from the view of platelet aggregation, hemorheology, TXB2/6-keto-PGF1 $\alpha$ and blood biochemistry in rat model. BMC veterinary research, 2016. 12(1): p. 108-108.

84. Mnafgui, K., et al., Anti-inflammatory, Antithrombotic and Cardiac Remodeling Preventive Effects of Eugenol in Isoproterenol-Induced Myocardial Infarction in Wistar Rat. Cardiovascular toxicology, 2016. 16(4): p. 336-344.

85. Raghavendra, R.H. and K.A. Naidu, Spice active principles as the inhibitors of human platelet aggregation and thromboxane biosynthesis. Prostaglandins Leukot Essent Fatty Acids, 2009. 81(1): p. 73-8.

86. Raffai, G., et al., Cinnamaldehyde and cinnamaldehyde-containing micelles induce relaxation of isolated porcine coronary arteries: role of nitric oxide and calcium. International journal of nanomedicine, 2014. 9: p. 2557-2566.

87. Aubdool, A.A., et al., TRPA1 activation leads to neurogenic vasodilatation: involvement of reactive oxygen nitrogen species in addition to CGRP and NO. Br J Pharmacol, 2016. 173(15): p. 2419-33.

88. Huang, J., et al., Cinnamaldehyde reduction of platelet aggregation and thrombosis in rodents. Thromb Res, 2007. 119(3): p. 337-42.

89. Takenaga, M., et al., In vitro effect of cinnamic aldehyde, a main component of Cinnamomi Cortex, on human platelet aggregation and arachidonic acid metabolism. J Pharmacobiodyn, 1987. 10(5): p. 201-8.

90. Lin, W.Y., et al., Anti-platelet aggregation constituents from Gynura elliptica. Phytochemistry, 2000. 53(8): p. 833-6.

91. Lin, W.Y., et al., Anti-platelet aggregation and chemical constituents from the rhizome of Gynura japonica. Planta Med, 2003. 69(8): p. 757-64.

92. Eccles, R., Menthol and related cooling compounds. J Pharm Pharmacol, 1994. 46(8): p. 618-30.

93. Murayama, M. and K.K. Kumaroo, Inhibitors of ex vivo aggregation of human platelets induced by decompression, during reduced barometric pressure. Thromb Res, 1986. 42(4): p. 511-6.

94. Nocella, C., et al., Impact of Tobacco Versus Electronic Cigarette Smoking on Platelet Function. American Journal of Cardiology, 2018. 122(9): p. 1477-1481.

95. Carnevale, R., et al., Acute Impact of Tobacco vs Electronic Cigarette Smoking on Oxidative Stress and Vascular Function. Chest, 2016. 150(3): p. 606-12.

96. Benowitz, N.L., Safety of nicotine in smokers with hypertension*. American Journal of Hypertension, 2001. 14(7): p. 731-732. 
97. Najem, B., et al., Acute Cardiovascular and Sympathetic Effects of Nicotine Replacement Therapy. Hypertension, 2006. 47(6): p. 1162-1167.

98. Pickering, T.G., The Effects of Smoking and Nicotine Replacement Therapy on Blood Pressure. The Journal of Clinical Hypertension, 2001. 3(5): p. 319-321.

99. Brinson, K., Effect of nicotine on human blood platelet aggregation. Atherosclerosis, 1974. 20(1): p. 137-140.

100. Conklin, D.J., Acute cardiopulmonary toxicity of inhaled aldehydes: role of TRPA1. Ann N Y Acad Sci, 2016. 1374(1): p. 59-67.

101. Jin, L., et al., Formaldehyde Induces Mesenteric Artery Relaxation via a Sensitive Transient Receptor Potential Ankyrin-1 (TRPA1) and Endothelium-Dependent Mechanism: Potential Role in Postprandial Hyperemia. Frontiers in physiology, 2019. 10: p. 277-277.

102. Lino-dos-Santos-Franco, A., et al., Differential effects of female sex hormones on cellular recruitment and tracheal reactivity after formaldehyde exposure. Toxicol Lett, 2011. 205(3): p. 327-35.

103. Lino-dos-Santos-Franco, A., et al., The putative role of ovary removal and progesterone when considering the effect of formaldehyde exposure on lung inflammation induced by ovalbumin. Clinics (Sao Paulo, Brazil), 2013. 68(12): p. 1528-1536.

104. Keselman, A., et al., Estrogen Signaling Contributes to Sex Differences in Macrophage Polarization during Asthma. The Journal of Immunology, 2017. 199(5): p. 1573.

105. Artero-Morales, M., S. González-Rodríguez, and A. Ferrer-Montiel, TRP Channels as Potential Targets for Sex-Related Differences in Migraine Pain. Frontiers in molecular biosciences, 2018. 5: p. 73-73. 


\section{APPENDICES}

\section{LIST OF ABBREVIATIONS}

$\begin{array}{ll}\text { ADP } & \text { Adenosine diphosphate } \\ \text { AHA } & \text { American Heart Association } \\ \text { ATP } & \text { Adenosine triphosphate } \\ \text { CBC } & \text { Complete blood count } \\ \text { CDC } & \text { Centers for Disease Control and Prevention } \\ \text { CHD } & \text { Coronary heart disease } \\ \text { CSR } & \text { Cigarette-smoking robot } \\ \text { CVD } & \text { Cardiovascular disease } \\ \text { DVT } & \text { Deep vein thrombosis } \\ \text { E-cig } & \text { Electronic cigarette } \\ \text { ENDS } & \text { Electronic nicotine delivery systems } \\ \text { HPHCs } & \text { Harmful or potentially harmful constituents } \\ \text { MCS } & \text { Mainstream cigarette smoke } \\ \text { MI } & \text { Myocardial infarction } \\ \text { NO } & \text { Nitric oxide } \\ \text { NTP } & \text { National Toxicology Program } \\ \text { OHSA } & \text { Occupational Safety and Health Administration } \\ \text { PE } & \text { Pulmonary embolism } \\ \text { PG } & \text { Propylene glycol } \\ \text { PPP } & \text { Platelet poor plasma } \\ \text { PRP } & \text { Platelet rich plasma } \\ \text { PLA } & \text { Platelet-leukocyte aggregate } \\ \text { ISO } & \text { International Standard of Organization } \\ & \end{array}$


TRPA1 Transient receptor potential ankyrin-1

TSP Total suspended particulate

VG Vegetable glycerin 


\section{SOURCES OF FUNDING}

This work was supported by the following grants: IPIBS, NIEHS T32ES011564, HL120163, HL120746, HL122676, and GM103492. 


\title{
CURRICULUM VITAE
}

\author{
Andre D. Richardson
}

University of Louisville School of Medicine

Department of Pharmacology and Toxicology

Diabetes \& Obesity Center

580 S. Preston Street (DOC 410)

Louisville, KY 40202

adrich10@louisville.edu

Lab: (502) 852-5836

Cell: (770) 468-1173

\section{EDUCATION}

2016-present University of Louisville, Louisville, KY

M.S. Pharmacology and Toxicology, In progress

2011-2013 Mercer University, Macon, GA

2014-2016 Nazareth College of Rochester, Rochester, NY

B.S. Cellular Toxicology

B.S. Biology

Minor in Chemistry

\section{HONORS}

2019- Awarded NIEHS T32 Training Grant

2019- $2^{\text {nd }}$ place poster presentation at the Cardiovascular Research Symposium - University of Louisville

2016- $3^{\text {rd }}$ best senior project presentation in the Biology Department - Nazareth College of Rochester

2015- $1^{\text {st }}$ place award for best presentation at CARS - Nazareth College of

Rochester

\section{RELATED EXPERIENCE}

May 2015- August 2015 - Undergraduate Research Intern

My research revolved around environmental toxicology and chemistry in which I tackled a very relevant dilemma surrounding the US, the effects of hydraulic fracturing (hydro-fracking) and heavy metal toxicity associated with hydrofracking. Under the guidance of Dr. Stephen Tajc, we were able to isolate and effectively utilize an organic bacterial byproduct capable of chelating toxic heavy 
metals from hydro-fracking wastewater solutions with efforts in bioremediation. During my time with Dr. Tajc, I have traveled to numerous states in the U.S. such as California, Colorado, Georgia, and New York to publicly present my work in conferences.

\section{RESEARCH}

2016-present IPIBS Graduate Fellowship \& T-32 Trainee Under mentorship of Dr. Daniel J. Conklin, my research focuses on any potential adverse effects that smoking conventional and electronic cigarettes may pose on the cardiovascular system, specifically platelet biology.

2014-2016 Undergraduate Student Research Under mentorship of Dr. Stephen Tajc, we investigated a potential small molecule compound capable of chelating and extracting metal (II) cations from aqueous solution. This approach has implications for bioremediation of heavy metals in hydro-fracking wastewater.

\section{PRESENTATIONS AND ABSTRACTS}

Richardson, A., Porter, M., and Tajc, S. Extracting metal (II) cations from aqueous solution using dipicolinic acid. Abstract for poster presentation, 2015 National American Chemical Society (ACS) Conference, Denver, Colorado, March 2015.

Richardson, A., Porter, M., and Tajc, S. Extracting metal (II) cations from aqueous solution using dipicolinic acid. Abstract for poster presentation, 2015 National American Chemical Society (ACS) Conference Regional at Genesee Community College, Genesee, New York, March 2015.

Richardson, A. and Tajc, S. Chelation of heavy metal (II) cations using 2,6pyridine dicarboxylic acid. Abstract for lecture presentation and for poster presentation, 2015 Creative Arts and Research Seminar (CARS). Rochester, New York, April 2015.

Richardson, A., Sobraske, C., Porter, M., Luta, E., Page, K., and Tajc, S. Organic soil bacterial byproduct as a chelating agent in bioremediation of hydro-fracking wastewater. Abstract for poster presentation, 2016 National American Chemical Society (ACS) Conference, San Diego, California, March 2016.

Richardson, A., Sobraske, C., and Tajc, S. Organic soil bacterial byproduct as a chelating agent in bioremediation of hydro-fracking wastewater. Abstract for 
poster presentation, 2016 Creative Arts and Research Seminar (CARS). Rochester, New York, April 2016.

Richardson, A. and Tajc, S. Extracting metal (II) cations using dipicolinic acid with efforts to bioremediate hydro-fracking wastewater. Abstract for Senior Comprehensive presentation, May 2016.

Richardson, A. and Conklin, DJ. Harmful Tobacco Smoke Constituents and Cardiovascular Disease: New Tobacco Products, New Concerns? Abstract for the University of Louisville Department of Pharmacology and Toxicology William J. Waddell Seminar Series, Louisville, Kentucky, March 2017.

Richardson, A., D'Souza, S., and Conklin, DJ. Electronic Cigarette Aerosol Aldehydes - Impact on Platelet Biology? Abstract for poster presentation, 2017 Ohio Valley Society of Toxicology (OVSOT), Louisville, Kentucky, July 2017.

Richardson, A., D'Souza, S., and Conklin, DJ. Do Electronic Cigarette-Generated Aldehydes Affect Platelet Biology? Abstract for poster presentation, 2017 Research! Louisville, Louisville, Kentucky, September 2017.

Richardson, A., D'Souza, S., and Conklin, DJ. Harmful and Potentially Harmful Constituents (HPHCs) and Cardiovascular Disease: Impact on Platelet Biology? Post-doc presentation for the Diabetes and Obesity Center of the University of Louisville, Louisville, Kentucky, October 2017.

Richardson, A., D'Souza, S., and Conklin, DJ. Electronic Cigarettes and Aerosolized Aldehydes: Direct impact on Human Platelet Rich Plasma. Abstract for Ohio Valley Society of Toxicology (OVSOT) at Purdue University, West Lafayette, Indiana, December 2017.

Richardson, A. and Conklin, DJ. Investigating e-cig-generated aldehydes' influence on hemostasis. Post-doc presentation for the Diabetes and Obesity Center of the University of Louisville, Louisville, Kentucky, February 2018.

Richardson, A. and Conklin, DJ. Do aldehydes in electronic cigarette smoke stimulate platelet-mononuclear cell aggregation in vivo? Post-doc presentation for the Diabetes and Obesity Center of the University of Louisville, Louisville, Kentucky, June 2018.

Richardson, A. and Conklin, DJ. Do aldehydes in electronic cigarette smoke stimulate platelet-mononuclear cell aggregation in vivo? Abstract for poster presentation, Ohio Valley Society of Toxicology (OVSOT) at Purdue University, West Lafayette, Indiana, August 2018.

Richardson, A. and Conklin, DJ. Do aldehydes in electronic cigarette smoke stimulate platelet-mononuclear cell aggregation in vivo? Abstract for poster presentation, 2018 Research! Louisville, Louisville, Kentucky, October 2018. 
Richardson, A. and Conklin, DJ. Thrombosis: Stuck on tobacco or switch to ecigarettes? Abstract for the University of Louisville Department of Pharmacology and Toxicology William J. Waddell Seminar Series, Louisville, Kentucky, October 2017.

Richardson, A. and Conklin, DJ. Thrombosis: Stuck on tobacco or switch to ecigarettes? Post-doc presentation for the Diabetes and Obesity Center of the University of Louisville, Louisville, Kentucky, October 2018.

Richardson, A. and Conklin, DJ. Do aldehydes in electronic cigarette smoke stimulate platelet-mononuclear cell aggregation in vivo? Abstract for poster presentation, Ohio Valley Society of Toxicology (OVSOT) at University of Louisville, Louisville, Kentucky, November 2018.

Richardson, A. and Conklin, DJ. Tobacco-Derived Aerosols and Thrombosis. $1^{\text {st }}$ Graduate Student Committee Meeting Presentation. University of Louisville, Louisville, Kentucky, December 2018.

Richardson, A. and Conklin, DJ. Smoking Out Unsaturated Aldehyde-Induced Platelet-Leukocyte Aggregation. Post-doc presentation for the Diabetes and Obesity Center of the University of Louisville, Louisville, Kentucky, April 2019.

Richardson, A. and Conklin, DJ. Do aldehydes in tobacco-derived aerosols stimulate platelet-mononuclear cell aggregation in vivo? Abstract for poster presentation (Won $2^{\text {nd }}$ place poster presenter), Cardiovascular Research Symposium, University of Louisville, Louisville, Kentucky, April 2019.

Richardson, A., Krivokhizhina, T., D'Souza, S., Srivastava, S., and Conklin, DJ. Phase-specific influences of electronic cigarette flavorings and acrolein on platelet aggregation. Abstract for poster presentation, 2019 Research! Louisville, Louisville, Kentucky, September 2019.

Richardson, A., Krivokhizhina, T., D'Souza, S., Srivastava, S., and Conklin, DJ. Phase-specific influences of electronic cigarette flavorings and acrolein on platelet aggregation. Platform presentation for the Ohio Valley Society of Toxicology (OVSOT) meeting, Mason, Ohio, October 2019.

\section{PROFESSIONAL SOCIETIES}

2017-present Ohio Valley Society of Toxicology (OVSOT)

2013-2016 American Chemical Society (ACS)

\section{EXTRACURRICULAR ACTIVITIES}

2014-2016 Nazareth College Division III Men's Volleyball Student-Athlete Our 2015 team were NCAA Division III Men's Volleyball National Semifinalist, finishing $3^{\text {rd }}$ national ranking in the final AVCA coaches' poll. 